\title{
DURABILIDADE DA MADEIRA DO GÊNERO Pinus TRATADA COM PRESERVANTES: AVALIAÇÃO EM CAMPO DE APODRECIMENTO
}

\author{
CRISTIANE TABARELLI BARILLARI
}

Dissertação apresentada à Escola Superior de Agricultura "Luiz de Queiroz", Universidade de São Paulo, para obtenção do título de mestre em Recursos Florestais, com opção em Tecnologia de Produtos Florestais.

PIR A C I C A B A

Estado de São Paulo - Brasil

Março - 2002 


\title{
DURABILIDADE DA MADEIRA DO GÊNERO Pinus TRATADA COM PRESERVANTES: AVALIAÇÃO EM CAMPO DE APODRECIMENTO
}

\author{
CRISTIANE TABARELLI BARILLARI \\ Bióloga
}

Orientador: Ivaldo Pontes Jankowsky

Dissertação apresentada à Escola Superior de Agricultura "Luiz de Queiroz", Universidade de São Paulo, para obtenção do título de mestre em Recursos Florestais, com opção em Tecnologia de Produtos Florestais.

P I R A C I C A B A

Estado de São Paulo - Brasil

Março - 2002 


\title{
Dados Internacionais de Catalogação na Publicação (CIP) DIVISÃo DE BIBLIOTECA E DOCUMENTAÇÃO - ESALQ/USP
}

\author{
Ba rilla ri, Cristia ne Taba relli \\ Durabilidade da madeira do gênero Pinus tratada com preservantes \\ : avaliação em campo de a pod recimento / Cristiane Tabarelli Ba rillari. - - \\ Piracicaba, 2002. \\ 68 p. : il. \\ Dissertação (mestrado) - - Escola Superior de Agricultura Luiz de \\ Queiroz, 2002. \\ Bibliografia. \\ 1. Durabilidade 2. Madeira (Tratamento) 3. Preservação da madeira \\ 4. Pinheiro I. Título
}

CDD 674.142

"Permitida a cópia total ou parcial deste documento, desde que citada a fonte - $\mathrm{O}$ autor" 
Aos meus pais,

Silvio Nieri Barillari e

Maria Lucia Tabarelli

Barillari

DEDICO. 


\section{AGRADECIMENTOS}

Ao Prof. Dr. Ivaldo Pontes Jankowsky, pela orientação, dedicação, auxilio e amizade.

A Escola Superior de Agricultura "Luiz de Queiroz", Universidade de São Paulo, pela possibilidade da realização do curso.

Ao CNPq pela bolsa concedida.

A todos os professores do curso pelos conhecimentos transmitidos.

Aos professores Dr. Evôneo Berti Filho, Dr. Geraldo Bortolleto Junior e Dr. Antonio Natal Gonçalves pela avaliação do trabalho.

Aos biólogos Sérgio Brazolin e Maria Beatriz Bacellar Monteiro do IPT pelas sugestões dadas ao trabalho e pela grande amizade e incentivo durante todos os anos de convívio.

Ao Rubens Dias Humphreys do IPT pela orientação nas análises estatísticas;

Ao Flávio Carlos Geraldo e Elaine Aparecida Campagnoli da Associação Brasileira dos Preservadores de Madeira pela colaboração,

Ao Dr. Ricardo Montagna do Instituto Florestal do Estado de São Paulo.

A colega Luciane K. Junqueira do laboratório de Entomologia Florestal ESALQ / USP, pela identificação dos cupins.

Aos pesquisadores Eduardo Amaral Batista e Luiz Carlos de Melo do Instituto Florestal do Estado de São Paulo, Estação Experimental de Mogi-Guaçu, pela colaboração durante as avaliações. 
Ao eng.agrônomo do Instituto de Botânica do Estado de São Paulo João Del - Giudice Neto pelos dados fornecidos.

Aos técnicos João Carlos Bancherie, Giovani Germano e Adeildo Paes de Toledo do Instituto Florestal de São Paulo, Estação Experimental de Mogi-Guaçu, pela ajuda durante as avaliações de campo.

Ao Ivo Rosa Filho pela ajuda, paciência e amizade do dia a dia.

Ao técnico do laboratório de Painéis a Base de Madeira, ESALQ / USP, ValdirFerreira Caldas.

Aos técnicos do IPT Reginaldo Ramos de Oliveira e Antonio Carlos Franco Barbosa pelo cuidado na preparação das lâminas e conversas animadoras.

Aos colegas do IPT Márcio Augusto Rabelo Nahuz, Geraldo Zenid, Gonzalo Antonio Carballeira Lopez, Raquel Amaral, Lígia Ferrari, Luiz Reis, Célia Vallin, Mariano Bergel, Sergio Matias, Sivia Toledo, Claudia Agostini, Vera de Sales, Silvia de Almeida pelo convívio e apoio.

Ao colega e amigo Fernando Resquin Perez.

As amigas Adriana Doniteze Carvalho Costa, Fabíola Figueroa, Cristiane Teixeira Toledo e Graziela Cury e pela disposição para auxiliar nos pequenos detalhes.

A amiga mais do que científica Viviane de Paula e Freitas pela companhia e auxílio nos mais diversos momentos.

Aos mais novos irmãos Ariel de Andrade e Renato Rocha Almeida por tudo.

A Bianca Moschetta de Moraes Sarmento pela ajuda e conforto em todos os momentos.

Ao André Brunckhorst pelo carinho e tranqüilidade transmitida nos momentos mais tensos.

A minha família por apoiar e compreender a distância.

A todos aqueles que direta ou indiretamente contribuíram para a realização dede trabalho. 


\section{SUMÁRIO}

Página

RESUMO

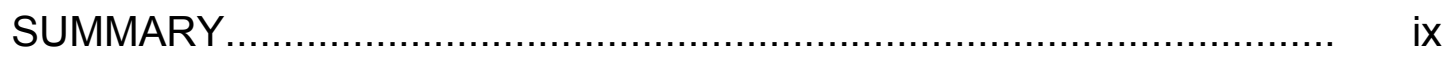

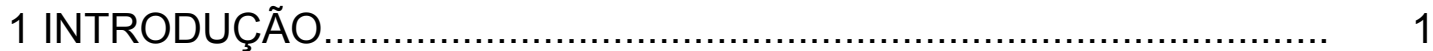

2 REVISÃO DE LITERATURA................................................... 4

2.1 Utilização da madeira proveniente de florestas plantadas.................. 4

2.2 Preservação de madeira.................................................................... 6

2.2.1 Preservantes de madeira........................................................... 12

2.3 Avaliação da qualidade do tratamento preservante........................... 15

2.4 Durabilidade da madeira tratada com preservantes químicos........... 16

2.5 Fungos deterioradores da madeira............................................... 20

2.6 Insetos xilófagos...................................................................... 23

2.7 Deterioradores identificados em campos de apodrecimento.............. 26

3 MATERIAL E MÉTODOS .............................................................. 29

3.1 Histórico do experimento............................................................ 29

3.2 Avaliação da durabilidade ........................................................... 34

3.3 Confirmação da sanidade biológica................................................ 37

3.4 Delineamento estatístico................................................................ 37

4 RESULTADOS E DISCUSSÃO........................................................ 39

4.1 Atividade biológica do campo..................................................... $\quad 39$

4.2 Avaliação da durabilidade........................................................... 41

4.3 Confirmação da sanidade biológica................................................. 52

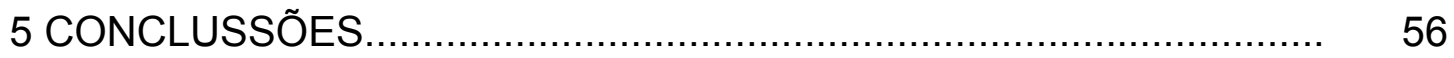

REFERÊNCIAS BIBLIOGRÁFICAS.................................................... 57

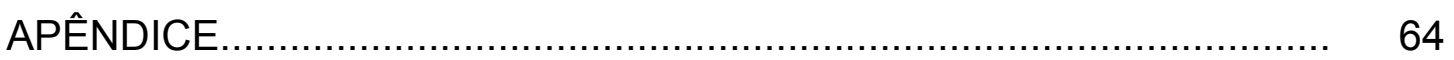




\title{
DURABILIDADE DA MADEIRA DO GÊNERO PinUS TRATADA COM PRESERVANTES: AVALIAÇÃO EM CAMPO DE APODRECIMENTO
}

\author{
Autora: CRISTIANE TABARELLI BARILLARI \\ Orientador: Prof. Dr. IVALDO PONTES JANKOWSKY
}

\section{RESUMO}

A madeira quando usada em contato direto com o solo, é atacada por agentes biológicos, principalmente fungos apodrecedores e cupins subterrâneos. Uma maneira de ampliar as possibilidades de utilização das espécies de baixa durabilidade natural, como as do gênero Pinus, é através do tratamento químico preservante. No entanto, faltam informações disponíveis que indiquem a durabilidade destas madeiras em serviço. A fim de se determinar a durabilidade da madeira do gênero Pinus tratada com preservantes, a Escola Superior de Agricultura "Luiz de Queiroz" e o Instituto Florestal do Estado de São Paulo instalaram, em 1980, campos de apodrecimento segundo método de ensaio sugerido pelo IUFRO (International Union of Forestry Research Organizations). As espécies utilizadas no ensaio foram o Pinus elliottii Engl. var. elliottii, o Pinus caribaea Mor. var. hondurensis, B \& G., o Pinus oocarpa Shied e o Pinus kesiya Royle ex Gordon; tratadas com 
os preservantes CCA tipos A, B e C, CCB e pentaclorofenol, em cinco níveis de retenção. Em continuidade ao projeto, foi inspecionado o campo instalado na Estação Experimental de Mogi-Guaçu, visando avaliar o estado de sanidade do material. A análise dos resultados obtidos até o momento, 21 anos de exposição demonstrou que não houve diferença no comportamento entre espécies. Os índices de comportamento mais altos (maior expectativa de durabilidade) correspondem aos tratamentos com CCA tipos A, B e C em retenções acima de $7,5 \mathrm{~kg} / \mathrm{m} 3$. Mesmo para os tratamentos que apresentaram os menores índices de comportamento (CCA tipo C com retenções de $5,0 \mathrm{~kg} / \mathrm{m}^{3}$ e CCB com $5,9 \mathrm{~kg} / \mathrm{m}^{3}$ ), é prevista uma durabilidade de 30 anos em serviço. 


\title{
DURABILITY OF PRESERVATIVE TREATED PinUS LUMBER: EVALUATION THROUGH FIELD STAKE TEST
}

\author{
Author: CRISTIANE TABARELLI BARILLARI \\ Adviser: Prof. Dr. IVALDO PONTES JANKOWSKY
}

\section{SUMMARY}

When used in ground contact, wood is deteriorated by biological agents, as root fungi and subterranean termites. A way to increase the use of wood species of low natural durability, as the Pinus lumber, is the preservative treatment. However, there is a lack of information indicating the durability of treated wood. In order to determine the durability of preservative treated Pinus lumber, the Escola Superior de Agricultura "Luiz de Queiroz" and the Instituto Florestal do Estado de São Paulo installed, in 1980, fields tests according to the IUFRO (International Union of Forestry Research Organizations). The species under test were Pinus elliottii Engl. var. elliottii, Pinus caribaea Mor. var. hondurensis, B \& G., Pinus oocarpa Shied and Pinus kesiya Royle ex Gordon; treated with the preservatives CCA types $A, B$ and $C, C C B$ and pentachlorophenol, in five retention levels. In continuity to the project, the material installed in the test site of Experimental Station of Mogi-Guaçu was inspected, to evaluate the degree of attack. The analysis of results obtained till 
now, after 21 years of exposure, demonstrated that there are no differences in durability related with species. The highest performance index (longer durability expectation) correspond to treatments with CCA types A, B and C in retentions above $7,5 \mathrm{~kg} / \mathrm{m} 3$. Even for the treatments that presented lowest performance index (CCA type C with retention of $5,0 \mathrm{~kg} / \mathrm{m}^{3}$ and CCB with $5,9 \mathrm{~kg} / \mathrm{m}^{3}$ ), the durability expectation is 30 years in service. 


\section{INTRODUÇÃO}

A madeira, por ser material de origem orgânica, dependendo das condições ambientais a que seja submetida, irá sofrer deterioração por agentes biológicos como microrganismos (bactérias e fungos), insetos (coleópteros e térmitas) e brocas marinhas (moluscos e crustáceos).

Dependendo dos organismos xilófagos presentes no local em que a madeira vai ser utilizada e das condições ambientais, mais ou menos favoráveis ao desenvolvimento dos mesmos, este material estará exposto a diferentes classes de risco. Em exposição permanente a umidificação, por contato direto com o solo, estará sujeita a deterioração rápida causada por fungos e térmitas subterrâneos; já em ambientes sem contato com a água o risco de deterioração é baixo e, quando ocorre, é devido ao ataque de cupins de madeira seca e brocas.

Quando a situação de uso da madeira a submete ao contato com o solo, torna-se necessário o uso de espécies de alta durabilidade natural ou de baixa durabilidade submetidas a tratamento preservante.

Considerando que as espécies de alta durabilidade natural são provenientes da floresta tropical, a utilização das espécies vindas de florestas plantadas e que possam ser submetidas ao tratamento preservante torna-se uma alternativa promissora.

A partir da lei $n^{\circ} 5.106$, de 02 de setembro de 1966, de incentivos fiscais, houve um aumento nos reflorestamentos no Brasil (Victor, 1970). Os principais gêneros plantados foram o Pinus e o Eucalyptus. E devido à boa adaptação as condições edafoclimáticas do Brasil, estes gêneros 
apresentaram altas velocidades de crescimento e potencial para diversos usos, incluindo a produção madeireira (Golfari, 1978). Contudo, a utilização da madeira de reflorestamentos como produtos que requeiram tratamento preservante está concentrada em postes e moirões de Eucalyptus.

De acordo com o último levantamento estatístico divulgado pela Associação Brasileira dos Preservadores de Madeira (ABPM, 1993), no biênio 1990-1991 a produção anual de madeira tratada foi da ordem de $175.000 \mathrm{~m}^{3}$, dos quais $39,4 \%$ foram dormentes (principalmente espécies tropicais), 36,6\% postes (exclusivamente de Eucalyptus) e 16,4\% de moirões (principalmente Eucalyptus).

A madeira do gênero Pinus possui características que permitem variada gama de aplicações, mas a carência de conhecimento e tradição no uso da madeira preservada, bem como a falta de especificações técnicas e informações sobre o comportamento em serviço, restringem sua utilização.

As especificações técnicas existentes no Brasil são normas da ABNT (Associação Brasileira de Normas Técnicas) e referem-se a postes, cruzetas, dormentes, moirões e bobinas de cabos elétricos produzidos principalmente com madeira do gênero Eucalyptus e outras espécies de madeiras tropicais.

Quando pretende-se ampliar os mercados de utilização da madeira tratada, a determinação da vida-média em serviço é de extrema importância. Para conhecer com segurança esta vida-média é necessário estimar a eficiência do tratamento preservante e realizar ensaios de durabilidade.

Dentre os diversos ensaios de durabilidade, Lopez \& Milano (1986) consideraram os ensaios de campo um ponto fundamental na avaliação do potencial de utilização de uma espécie de madeira ou preservante.

Ao avaliar a durabilidade da madeira do gênero Pinus submetida a tratamento preservante, a presente pesquisa dá continuidade ao 
trabalho iniciado em 1980 pela Escola Superior de Agricultura "Luiz de Queiroz" em conjunto com o Instituto Florestal do Estado de São Paulo.

O objetivo principal foi avaliar a durabilidade da madeira de espécies do gênero Pinus (Pinus elliottii Engl. var. elliottii, Pinus caribaea Mor. var. hondurensis, B \& G., Pinus oocarpa Shied e Pinus kesiya Royle ex Gordon) tratadas, após 21 anos de exposição em campo de apodrecimento, com base no índice de comportamento (estado de sanidade da madeira); buscando também identificar possíveis diferenças entre as espécies e o efeito do preservante e do nível de retenção na durabilidade da madeira tratada. 


\section{REVISÃO DE LITERATURA}

\subsection{Utilização da madeira proveniente de florestas plantadas}

Em 1999, a área total de florestas plantadas dos gêneros Pinus e Eucalyptus era de $1.428 .719,2$ ha, onde, a madeira de Pinus representava $31 \%$ e o Eucalyptus $69 \%$ do total. As espécies de madeira do gênero Pinus mais plantadas nesse ano foram $P$. taeda $(50 \%), P$. caribaea var.hondurensis (10\%) e P.elliottii (menos de 10\%) (Associação Brasileira de Celulose e Papel BRACELPA, 1999).

A partir das informações disponíveis, estima-se que a produção de madeira e produtos derivados, considerando-se os gêneros Pinus e Eucalyptus (florestas plantadas), foi da ordem de $813.837,4 \mathrm{Mm}^{3}$ no ano de 2000.

Segundo projeção da BRACELPA, em 2001 a produção de celulose foi de 7,4 Mt e a de papel 7,3 Mt (Tabacof, 2001). No setor energético, foram produzidos $127,3 \mathrm{Mm}^{3}$ de lenha e $74,2 \mathrm{Mm}^{3}$ de carvão, durante o ano de 1999 (Ministério de Minas e Energia, 2000). Dentre os produtos de madeira sólida, a Associação Brasileira da Industria de Madeira Processada Mecanicamente, estima uma produção de $2,25 \mathrm{Mm}^{3}$ de compensados, $720 \mathrm{Mm}^{3}$ de madeira serrada e $1,1 \mathrm{Mm}^{3}$ de PMVA (produtos de maior valor agregado), no ano de 2001 (ABIMCI, 2001). Segundo Geraldo ${ }^{1}$, a produção estimada de madeira tratada em autoclave no ano de 2000 foi da ordem de $560.000 \mathrm{~m}^{3}$. 
Em 1999, a utilização da madeira do gênero Pinus na produção de pasta celulósica representava aproximadamente $33 \%$ da produção, a madeira do gênero Eucalyptus $61 \%$, e o restante dividido entre outros tipos de fibras (BRACELPA, 1999).

Cerca de $95 \%$ da matéria-prima empregada na produção de carvão vegetal no Estado de São Paulo é oriunda de reflorestamentos, principalmente do gênero Eucalyptus (PRÓ-CARVÃO, 2000). Estima-se que no ano de 2000 as madeiras de reflorestamento, principalmente do gênero Pinus, tenham representado $40 \%$ da produção nacional de compensados e $33,6 \%$ da produção de madeira serrada, e sendo considerada, também, como a principal matéria prima na produção de PMVA (ABIMCl, 2001). Já na produção de madeira preservada, Geraldo ${ }^{1}$ estima que o gênero Pinus corresponda a apenas $3 \%$ do total produzido.

Nas regiões Sul e Sudeste do Brasil encontram-se $40 \%$ das unidades produtoras de madeira serrada do país. A maioria dessas indústrias utilizam madeira do gênero Pinus; no entanto, o baixo grau tecnológico e a mão-de-obra pouco qualificada tornam tal atividade pouco competitiva $(\mathrm{ABIMCl}$, 1999).

Na década passada, Watai (1990) preconizava a intensificação das pesquisas tecnológicas visando utilizar com maior intensidade as madeiras de reflorestamento em substituição às nativas. Como ponto favorável na utilização de espécies do gênero Pinus, o autor cita sua consagração no mercado interno, principalmente no setor de manufaturados (móveis) e a exportação para países industrializados. Por outro lado, esta madeira apresenta baixa resistência natural ao ataque de organismos xilófagos.

Uma forma de agregar valor à madeira serrada do gênero Pinus é através do tratamento químico preservante adequado, que irá conferir a mesma maior durabilidade em uso.

\footnotetext{
${ }^{1}$ GERALDO, F. C (Montana Química). Comunicação pessoal, 2001
} 
Para que a indústria de preservação de madeiras se desenvolva, são necessárias mudanças no enfoque de utilização da madeira tratada no Brasil. Jankowsky (1993), reforça a importância de conscientizar os consumidores e propiciar base técnica para incrementar o uso da madeira tratada na construção habitacional.

\subsection{Preservação de madeiras}

Cavalcante (1983), define a preservação de madeiras como o conjunto de produtos, métodos, técnicas e pesquisas destinadas a alterar, medir ou estudar a durabilidade da madeira, podendo ser dividida em preservação natural, indireta, biológica e química.

A preservação indireta pode ser conceituada como o tratamento do meio em que a madeira está sendo utilizada; enquanto que a preservação biológica envolve o emprego de organismos vivos na prevenção ao ataque dos organismos xilófagos. Moraes (1996a), conceitua como preservação natural a utilização da madeira de forma a evitar a ação dos agentes deterioradores, protegendo-a do contato com o solo (apoiando as edificações sobre bases de concreto ou pedra) e das fontes de umidade (através de beirais largos), e como preservação química, a introdução de produtos químicos dentro da estrutura da madeira, visando torná-la tóxica aos organismos que a utilizam como fonte de alimento.

A preservação química da madeira é provavelmente o método mais antigo. O primeiro registro foi feito por Noé, que teria sido instruído por Deus para que protegesse o casco de sua embarcação com piche (Richardson, 1993).

Apesar dos possíveis riscos no manuseio e uso de biocidas, a preservação química ainda é a forma mais usual na prevenção do ataque biológico. Os métodos para aplicação do preservante na madeira podem ou não incluir pressão superior a ambiente como auxiliar da impregnação. 
Os tratamentos sob pressão são considerados os mais eficientes, em razão da distribuição e penetração do preservante na peça tratada. Tais tratamentos são classificados em processos de célula cheia e de célula vazia, em função da maneira pela qual é feita a distribuição do preservante nas fibras da madeira (Hunt \& Garrat, 1953). As madeiras tratadas por esses métodos podem ser utilizadas em qualquer situação, mesmo nas que apresentam alto índice de ataque por organismos xilófagos, como no caso de contato direto com o solo (Rocha, 2000).

O início das atividades industriais de preservação de madeiras teve como base o tratamento de dormentes pela indústria ferroviária e o uso de postes preservados para redes de distribuição de energia elétrica, telefone e telégrafo. Na Austrália, Estados Unidos, Inglaterra, Alemanha, Japão, Irã, Portugal, Espanha e Brasil as primeiras industrias de preservação de madeiras foram instaladas com o objetivo de tratar postes e dormentes (Cockcroft, 1979; Cockcroft, 1981; Greaves, 1984; Cockcroft \& Willeitner, 1981; Amemiya \& Cockcroft, 1982; Niloufari \& Cockcroft, 1984; Reimão \& Cockcroft, 1985; Roma \& Cockcroft, 1983; Cavalcante \& Cockcroft, 1984).

Outros países desenvolveram a indústria de preservação tratando madeira com outras finalidades, como para construção civil na Bélgica, (Stevens \& Cockcroft, 1981) ou para construção de diques na Holanda (Burgers et al., 1985).

Em geral, os principais produtos tratados são postes de eletrificação rural e de telefonia, cruzetas, dormentes de estrada de ferro, madeiras usadas na agricultura (cercas, estacas), madeiras estruturais para a construção civil, madeiras para jardins e parques, compensados, produtos de marcenaria, madeiras para mineração, para proteção de estradas, madeiras serradas e madeiras para construção de portos, diques, etc (Moraes, 1996b).

Em 1971, a porcentagem de residências de madeira nos E.U.A. era de $83 \%$, no Canadá de $90 \%$ e no Japão $98 \%$, enquanto que no Brasil, cuja área florestal é bem maior do que a dos demais países, as casas construídas 
com estruturas de madeira não chegavam a $2 \%$ do total (Freitas, 1971). Segundo o mesmo autor, o baixo índice de utilização da madeira como material básico na construção de habitações se deve muitas vezes a problemas econômicos, sociais ou de infra-estrutura da indústria madeireira. Dentre os problemas sócio-culturais destacam-se a colonização portuguesa com construções em alvenaria, a popularização da idéia que casas de madeira são símbolo de baixo "status" social (com exceção nos estados da região sul do Brasil), o baixo poder aquisitivo das populações e a escassez de informações sobre utilização da madeira nos programas de formação profissional de arquitetos e engenheiros.

Durante os últimos 30 anos, o mercado de madeira tratada mudou, decrescendo a participação dos produtos tradicionais (postes e dormentes) e aumentando a importância dos elementos construtivos em madeira. Como exemplo, o volume de postes e dormentes produzidos nos E.U.A. não é muito diferente do volume produzido há 30 anos (quando estes dominavam o mercado), contudo o consumo de componentes para construção em madeira tratada cresceu, sendo hoje responsável por $70 \%$ de toda a produção (Preston, 2000).

A Tabela 1 mostra a situação da indústria de preservação de madeiras em diversos países no ano de 1996. Nesta, destaca-se o consumo per capita dos seguintes países: Nova Zelândia, Finlândia, E.U.A., Suécia e Noruega, sendo o Brasil o país com menor consumo. O número de usinas de tratamento no Brasil é um dos menores, entre os países citados. No entanto, a produção média por usina é a segunda maior, provavelmente devido à presença de usinas de grande porte. 
Tabela 1. Produção de madeira tratada nos principais países produtores.

\begin{tabular}{|c|c|c|c|c|c|}
\hline País & Ano & $\begin{array}{l}\text { Número de } \\
\text { usinas de } \\
\text { tratamento }\end{array}$ & $\begin{array}{l}\text { Produção } \\
\text { Anual } \\
\left(1.000 \mathrm{~m}^{3}\right)\end{array}$ & $\begin{array}{l}\text { Produção } \\
\text { média por } \\
\text { usina }\left(100 \mathrm{~m}^{3}\right)\end{array}$ & $\begin{array}{c}\text { Produção em } \\
1000 \mathrm{~m}^{3} / 100.000 \\
\text { habitantes }\end{array}$ \\
\hline E.U.A & 1990 & 540 & 16.590 & 30,7 & 6,7 \\
\hline Inglaterra & 1978 & 640 & 2.000 & 3,1 & 3,6 \\
\hline Nova Zelândia & 1982 & 324 & 1.179 & 3,6 & 38,0 \\
\hline África do Sul & 1984 & 210 & 905 & 4,3 & 3,5 \\
\hline Japão & 1982 & 174 & 557 & 3,2 & 0,5 \\
\hline Brasil & 1984 & 45 & 477 & 10,6 & 0,4 \\
\hline Suécia & 1982 & 242 & 461 & 1,9 & 5,6 \\
\hline Austrália & 1984 & 208 & 402 & 1,9 & 2,6 \\
\hline Finlândia & 1982 & 80 & 350 & 4,4 & 7,4 \\
\hline Espanha & 1983 & 33 & 346 & 10,5 & 0,9 \\
\hline Bélgica & 1981 & 80 & 206 & 2,56 & 2,0 \\
\hline Noruega & 1982 & 110 & 200 & 1,8 & 4,9 \\
\hline Holanda & 1985 & 26 & 190 & 7,3 & 1,3 \\
\hline Portugal & 1985 & 16 & 80 & 5,0 & 0,8 \\
\hline
\end{tabular}

Fonte: Moraes, 1996a.

No Brasil, o primeiro documento sobre preservação de madeiras data de 1587, e foi escrito por um fazendeiro português que descreveu detalhadamente $\mathrm{o}$ ataque de térmitas subterrâneos e brocas, ocorridos em construções. Citou ainda, o ataque de perfuradores marinhos e a durabilidade natural de algumas espécies de madeira em diferentes ambientes (Cavalcante \& Cockcroft, 1984). 
Como em outros países, a preservação de madeiras se instalou no Brasil devido ao desenvolvimento das estradas de ferro em 1854 e com a produção e distribuição de energia elétrica, em 1883 (Cavalcante, 1986).

A primeira usina de preservação de madeira sob pressão foi importada da Inglaterra em 1900, e instalada pelo governo brasileiro em Juiz de Fora, Minas Gerais. Começou a operar em 1902 no tratamento de dormentes para estrada de ferro usando creosoto como preservante (Moraes, 1996a).

A segunda usina, de cunho privado, foi inaugurada em 1945 e visava o tratamento de postes de eucalipto. De 1960 em diante, houve um crescimento constante no número de usinas em operação, concentradas principalmente nas regiões sul e sudeste (Cavalcante \& Cockcroft, 1984).

Entre 1940 e 1970, houve uma grande expansão da demanda de postes de madeira tratada, mas sem acompanhamento de um respaldo técnico que garantisse a qualidade do produto final; o que, aliado à ausência de técnicas adequadas e um controle de qualidade efetivo, fez com que a vida útil dos postes não fosse a esperada. Isto fez com que o produto caísse em descrédito e expandisse o mercado de postes de concreto em detrimento do mercado dos postes de madeira (Moraes,1996a).

Em 1969, foi fundada a ABPM (Associação Brasileira dos Preservadores de Madeira) e com isso aumentou o interesse na preservação de madeiras. Em 1972 foram publicadas as portarias que regulamentaram a produção de madeira tratada e dos preservantes de madeira, contribuindo para melhorar o suporte técnico aos produtores.

Entre 1970 e 1980 o número de estabelecimentos da indústria de preservação da madeira aumentou em mais de $300 \%$, crescimento explicado pelo grande desenvolvimento brasileiro nos setores de transportes e energia. Por ser uma indústria extremamente dependente de obras estatais, a partir de 1980 a indústria de madeira preservada começou a decrescer devido à retração econômica no país. 
Na Tabela 2 é possível verificar que a produção de madeira tratada foi decrescente ao longo da década de 80 , com uma ligeira tendência de recuperação no início da década de 90.

Tabela 2. Produção anual de madeira tratada no Brasil no período de 1987 a 1991.

\begin{tabular}{|c|c|c|c|c|c|c|c|}
\hline \multirow[t]{2}{*}{ Produtos } & \multicolumn{5}{|c|}{ Produção $\left(\mathrm{m}^{3}\right)$ / ano } & \multicolumn{2}{|c|}{ Média } \\
\hline & 1987 & 1988 & 1989 & 1990 & 1991 & volume & $(\%)$ \\
\hline Poste & 92.499 & 84.204 & 60.525 & 94.438 & 34.666 & 73.266 & 40.2 \\
\hline Dormente & 116.256 & 65.550 & 27.523 & 43.379 & 94.489 & 63.439 & 38.1 \\
\hline Cruzeta & 1.868 & 3.312 & 1.738 & 2.171 & 1.678 & 2.153 & 1.2 \\
\hline Moirão & 34.422 & 26.502 & 28.079 & 29.901 & 27.586 & 29.098 & 16.0 \\
\hline Serrados & 658 & 300 & 531 & 203 & 1.694 & 677 & 0.4 \\
\hline Outros & 3.830 & 7.263 & 5.508 & 7.315 & 13.780 & 7.539 & 4.1 \\
\hline Total & 249.533 & 186.131 & 123.904 & 177.407 & 173.893 & 182.174 & 100.0 \\
\hline
\end{tabular}

Entre 1995 e 1996 existiam 68 usinas de preservação de madeira sob pressão, com capacidade de produção anual estimada em $865.000 \mathrm{~m}^{3}$. Destas, 14 estavam inativas e 14 pertenciam a empresas estatais dos setores ferroviário e elétrico (que tratam madeira somente para o consumo próprio). Das 40 usinas restantes, tinha-se a capacidade anual de produção estimada em $680.000 \mathrm{~m}^{3}$ (Moraes, 1996a). 
Segundo informações da ABPM (Geraldo²), atualmente estão em operação 80 usinas, estimando-se uma produção de $560.000 \mathrm{~m}^{3}$ de madeira preservada durante o ano de 2000. A maior parte dessa produção é destinada ao segmento rural, seguido pelo elétrico, ferroviário e de madeira serrada. Este último, contudo, ainda é inexpressivo (de 3 a $5 \%$ do volume total produzido).

\subsubsection{Preservantes de madeira}

As características essenciais de um produto preservante de madeira são: a baixa toxicidade às pessoas, animais e plantas; a proteção da mesma contra o ataque de organismos xilófagos e a retenção ao longo dos anos (Wilkinson, 1979). Além disso, é importante que este produto seja econômico, ou seja, que a sua aplicação não eleve muito os custos de obtenção da madeira preservada.

Os preservantes são classificados de acordo com suas características físicas e químicas, podendo ser divididos em dois grandes grupos, o dos preservantes oleosos e oleossolúveis e o dos preservantes hidrossolúveis (Hunt \& Garrat, 1953).

Os principais preservantes para utilização em contato com o solo são o creosoto (preservante oleoso), o pentaclorofenol (preservante oleossolúvel), o CCA (arsenato de cobre cromatado) e o CCB (borato de cobre cromatado), ambos preservantes hidrossolúveis.

O creosoto é usado pela industria de preservação desde o início do século XIX (Cavalcante, 1979). É um preservante oleoso proveniente da destilação do alcatrão da hulha, geralmente empregado no tratamento de postes e dormentes. Os compostos químicos presentes no creosoto podem ser classificados em três categorias: ácidos de alcatrão (aproximadamente 15\% do creosoto); bases de alcatrão (cerca de 5\%) e hidrocarbonetos (80\%).

\footnotetext{
${ }^{2}$ GERALDO, F. C. (Associação Brasileira dos Preservadores de Madeira). Comunicação pessoal, 2001
} 
Pode ainda apresentar formulações com substâncias químicas que fortalecem seu desempenho, como o pentaclorofenol, o naftenato de cobre e o enxofre (Lepage, 1986).

Segundo Besner et al. (1999), o creosoto sofre modificações quantitativas na madeira intemperizada. Apesar disso, as alterações qualitativas são pequenas se comparadas aos preservativos hidrossolúveis e, mesmo após vários anos de uso, o creosoto residual é capaz de evitar o ataque de fungos.

A aplicação deste preservante pode, ainda melhorar as propriedades mecânicas da madeira (Banda \& Twesigye-omwe, 1997). No entanto, existem algumas limitações quanto ao uso do creosoto em ambientes internos ou próximo de pessoas e animais, devido à volatilização de compostos orgânicos e ao seu odor forte (Marer \& Grimes, 1992). Outra desvantagem é que a madeira tratada com creosoto apresenta mudança pronunciada de coloração e não aceita aplicação de tintas ou vernizes, o que em determinadas condições de uso não é uma característica desejável.

O pentaclorofenol começou a ser comercializado na Alemanha no início do século 20 e é utilizado nos Estados Unidos desde 1938 (Wilkinson, 1979). Segundo Cavalcante (1979), este produto começou a ser utilizado no Brasil em 1957, sendo localmente produzido entre 1967 e 1968. Sua fórmula molecular é $\mathrm{C}_{6} \mathrm{Cl}_{5} \mathrm{OH}$ e o principal solvente utilizado é o petróleo bruto (Rocha, 2000).

O pentaclorofenol confere longa proteção à madeira devido as características de ser altamente tóxico a organismos xilófagos e resistente a lixiviação devido a insolubilidade em água (Lepage, 1986). Por ser um produto altamente tóxico ao homem e animais, sua utilização sofreu fortes restrições impostas na portaria $\mathrm{n}^{0} 329$ do Ministério da Agricultura, Pecuária e Abastecimento, de 02 de setembro de 1985 (Agência Nacional de Vigilância Sanitária, 2001). 
A maioria dos produtos hidrossolúveis, tanto à base de cobre, cromo e arsênio como à base de cobre, cromo e boro, começaram a ser utilizados industrialmente nas décadas de 50 e 60 (Cavalcante,1979).

Os ingredientes ativos do preservante CCA (arsenato de cobre cromatado) são o $\mathrm{CrO}_{3}$ (cromo), o $\mathrm{CuO}$ (cobre) e o $\mathrm{As}_{2} \mathrm{O}_{5}$ (arsênio). Ao longo dos anos, as porcentagens desses ingredientes foram alteradas, resultando na existência de três formulações básicas atualmente normatizadas e disponíveis no mercado: o tipo A, o tipo B e o tipo C (Lepage, 1986).

O CCA apresenta repelência à água devido à formação de um complexo polimérico, tornando o preservante insolubilizado no interior da madeira e resistente à lixiviação (Wilkinson, 1979). O mesmo autor considera a durabilidade conferida as madeiras tratadas com CCA semelhante a das tratadas com creosoto.

Após o tratamento, a madeira adquire coloração esverdeada, não exala odores nem vapores tóxicos irritantes ao homem e não aumenta a combustibilidade, além de conferir proteção contra fungos, insetos e brocas marinhas (Lepage, 1986). Seu uso é recomendado para ambientes internos, externos e madeiras com ou sem contato com o solo. Contudo, diversos trabalhos realizados em campo indicam que o desempenho do produto cai sensivelmente em regiões com alta incidência de térmitas (Eaton, 1993).

Um dos inconvenientes apresentados pelo CCA é a perda de resistência da madeira tratada, sobretudo da tenacidade, que está relacionada com o aumento da retenção (Evans et al., 2000). Essa perda de resistência parece estar ligada a alterações no $\mathrm{pH}$ ocorridas no primeiro estágio da reação de insolubilização do CCA.

O uso da madeira tratada com CCA apresenta algumas limitações, como o seu uso em contato com o cimento (rico em Ca) e sob alta umidade, o que reduz o poder deste preservativo contra alguns organismos xilófagos. Adicionalmente, há a possibilidade de alterações tanto quantitativas como qualitativas devido à lixiviação do preservante quando as madeiras são 
submetidas a intemperismo (Besner et al., 1999). No entanto, cerca de $80 \%$ de toda a madeira tratada no mundo é impregnada com este produto (Rocha, 2000).

O CCB (borato de cobre cromatado) ou sais de Wolmam é um composto que tem como ingredientes ativos o $\mathrm{CuO}$ (cobre), o $\mathrm{Cr}_{2} \mathrm{O}_{3}$ (cromo) e o B (boro), e começou a ser comercializado na Alemanha no início da década de 60. No Brasil, é utilizado no tratamento de postes com retenção mínima de $9,6 \mathrm{~kg} / \mathrm{m}^{3}$ (Lepage, 1986). Nos E.U.A., é utilizado no tratamento de madeira serrada (Hunt \& Garrat, 1953). Existem dúvidas em relação a sua resistência a lixiviação e eficiência, a longo prazo, no combate a insetos (Lepage, 1986).

\subsection{Avaliação da qualidade do tratamento preservante}

O controle de qualidade em madeira tratada é feito normalmente através da determinação de retenção, penetração e distribuição do preservante na madeira. Tanto a penetração quanto à retenção do preservante são influenciadas por características relacionadas à madeira e ao processo de tratamento utilizado (Galvão et al., 1967).

Uma das etapas da avaliação de eficácia em um determinado preservante no combate a deterioração biológica compreende os ensaios de durabilidade. Estes podem ser ensaios de laboratório, simuladores acelerados de campo ou ensaios de campo (Lopez \& Milano, 1986).

Para Nicholas (1985), a madeira quando está em contato com o solo deteriora muito mais rápido do que fora dele, devido ao equilíbrio da umidade da madeira em contato com o solo úmido, a possibilidade de lixiviação de produtos preservantes e a uma grande quantidade de microorganismos que colonizam a madeira e/ou causam degradação do preservante.

Os ensaios de campo, conhecidos como campos de apodrecimento, expõem a madeira ao solo, às intempéries do ambiente e a uma vasta gama de microorganismos e insetos xilófagos. 
Avaliando as condições da madeira durante o período de ensaio, pode-se verificar os organismos que estão deteriorando o material além de possibilitar a estimativa da vida média em serviço (Lopez \& Milano, 1986).

Van Acker (2000), considera os campos tropicais preferenciais quando se espera obter resultados reais em um período de tempo razoavelmente curto, porém pouco se sabe sobre critérios de seleção de um campo e sobre comparações de diferentes locais de teste.

Outra desvantagem dos ensaios de campo com estacas de madeira é a obtenção de dados em longo prazo, ou seja, entre 10 e 20 anos. No entanto, fornece informações próximas das condições de uso, pois a madeira fica exposta à ampla biodiversidade xilófaga do habitat (Jesus et al., 1998).

Segundo Lopez \& Milano (1986), apesar dos altos custos envolvidos nos ensaios de campo, este é o único método onde é possível prever o desempenho que a madeira apresentará em serviço e o potencial de utilização da madeira natural ou preservada.

Um método de ensaio muito utilizado em estudos sobre preservação de madeiras é o "Método Padrão sugerido pela IUFRO para Ensaios de Campo com Estacas de Madeira", descrito por Lepage (1970).

A fim de estimar a vida média em serviço das madeiras, recomenda - se utilizar a curva de durabilidade média desenvolvida por McLean (Hunt \& Garrat, 1953). Estas são curvas de probabilidade baseadas na porcentagem de remoção ou falhas após determinado período de tempo. A partir de $10 \%$ de peças falhas, as durações médias prováveis são estimadas em função do período de tempo transcorrido do ensaio. Quando $60 \%$ das peças falham, considera-se atingida a duração média provável ou vida média. 


\subsection{Durabilidade da madeira tratada com preservantes químicos}

A Tabela 3 mostra, em linhas gerais, os resultados obtidos por diversos autores na avaliação da durabilidade de várias espécies de madeiras, com e sem tratamento preservante, em campos de apodrecimento.

Tabela 3. Durabilidade de madeiras com e sem tratamento, em ensaios de campo.

\begin{tabular}{|c|c|c|c|}
\hline Espécie de Madeira & Tratamento & Durabilidade & Referência \\
\hline Pinus elliottii & sem tratamento & 8 meses & Lopez, 1984 \\
\hline Pinus spp & sem tratamento & $<1$ ano & Fernandes et al., 1990 \\
\hline $\begin{array}{l}\text { Pinus silvestris } \\
\text { (cerne) }\end{array}$ & sem tratamento & $3-5$ anos & Reis, 1965 \\
\hline Pinus spp & $\begin{array}{l}\text { Hidrossolúveis } \\
\text { (c/pressão) }\end{array}$ & $12-16$ anos & Jankowsky et al., 1989 \\
\hline Pinus silvestris & CCA & + de 15 anos & Hedley et al., 2000 \\
\hline Pinus radiata & CCA & $19-43$ anos & Hedley et al., 2000 \\
\hline Pinus radiata & CCB & 20 anos & Hedley et al., 2000 \\
\hline Pinus silvestris & creosoto & + de 15 anos & Reis, 1965 \\
\hline Pinus silvestris & pentaclorofenol & $3-5$ anos & Reis, 1965 \\
\hline
\end{tabular}

Os dados da Tabela 3 mostram uma maior durabilidade do cerne da madeira de Pinus silvestris em relação a madeira de Pinus elliottii, que provavelmente se deve a diferenças na durabilidade natural das espécie de madeira estudadas. No entanto, independentemente da espécie de madeira do 
gênero Pinus, nota-se a baixa durabilidade, quanto exposta a campos de apodrecimento sem tratamento preservante. Já as madeiras tratadas com preservantes hidrossolúveis apresentam durabilidade acima de 15 anos, ou seja, a madeira do gênero Pinus quando tratada passa a ser considerada durável.

Segundo Hedley et al. (2000), o alburno da madeira de Pinus radiata tratada com CCA base sal e óxido nas retenções de 4,5 a $4,7 \mathrm{~kg} / \mathrm{m}^{3}$ e submetidas a cinco campos de teste distintos, após 25 anos de exposição apresentaram desempenho diferenciado em relação aos campos. Para os dois produtos (base sal e óxido), em 3 dos campos o Índice de Comportamento foi igual a 70 (deterioração moderada). Em apenas um dos campos o CCA base óxido apresentou menor Índice de Comportamento ( 40 = deterioração intensa) em comparação ao CCA base sal (40 a 70 = deterioração moderada a intensa). Essas diferenças nos Índices de Comportamento podem ser explicadas pelas condições ambientais diferenciadas nos campos.

No mesmo trabalho, os Índices de Comportamento da madeira de Pinus radiata tratada com CCB foram relatados após aproximadamente 20 anos de exposição. Estes índices variam conforme os diferentes campos, sendo que, em dois campos apresenta índice 70 (deterioração moderada), em um campo foi 90 (deterioração incipiente), e em dois campos foi 40 (deterioração intensa).

Van Acker (2000), comparou a durabilidade de várias espécies de folhosas sem tratamento e com tratamento. As madeiras consideradas de durabilidade natural moderada ou baixa, quando tratadas com CCA tipo C na retenção de $12 \mathrm{~kg} / \mathrm{m}^{3}$, mostraram potencial de vida útil satisfatória; enquanto que as madeiras consideradas não duráveis parecem necessitar de retenções mais elevadas para resistir às condições do ensaio.

$\mathrm{Na}$ Tabela 4 estão expressos os valores médios do Índice de Comportamento obtidos em estudo realizado por Lopez et al. (1984), com madeira de Pinus elliotti tratada com preservantes hidrossolúveis CCA tipo A, 
CCA tipo C e CCB, após quatro anos de exposição, em diversos campos de apodrecimento no Estado de São Paulo.

Tabela 4. Índice de Comportamento da madeira de Pinus elliotii .

\begin{tabular}{cccc}
\hline Retenções $\left(\mathbf{k g} / \mathbf{m}^{3}\right)$ & CCA tipo A & $\begin{array}{c}\text { Índice de Comportamento } \\
\text { CCA tipo C }\end{array}$ & CCB \\
\hline 4,9 & 97 & 100 & 94 \\
6,9 & 97 & 100 & 95 \\
9,6 & 97 & 99 & 97 \\
13,5 & 99 & 98 & 97 \\
\hline
\end{tabular}

Fonte: Lopez et al. (1984).

Nota-se por estes dados que a performance dos produtos foi similar em todos os níveis de retenção testados, até a data da avaliação, e que não há diferença no Índice de Comportamento que possa diferenciar o desempenho dos produtos.

A influência do ambiente (clima, temperatura e tipo de solo) no desempenho da madeira de Pinus radiata tratada com CCA e CCB foi avaliada por Hedley et al., (2000). No campo de baixa umidade, o CCA mostrou ser mais eficiente no controle da deterioração que o CCB; no campo com maior umidade (pluviosidade maior que $3.500 \mathrm{~mm} / \mathrm{ano}$ ), o CCB teve um melhor desempenho que o CCA e no campo quente e úmido (pluviosidade de $2.000 \mathrm{~mm} / \mathrm{ano}$ ) o desempenho do CCA foi semelhante ao do CCB.

Tanto no campo onde a precipitação foi baixa (800 mm/ano), com solo arenoso e bem drenado, quanto no campo onde a precipitação foi um pouco maior ( $1.400 \mathrm{~mm} / \mathrm{ano}$ ), solo pedregoso, com lama e sujeito a períodos de seca no verão, a principal causa das falhas foi a deterioração causada por fungos de podridão parda. Este fato confirma que alguns fungos desse tipo são 
mais tolerantes a períodos com pouca disponibilidade de água do que os microrganismos causadores de outros tipos de deterioração.

Van Acker (2000), avaliou, em regiões tropicais, a durabilidade de madeiras tratadas com CCA em três campos de apodrecimento com diferentes tipos de solo e condições micro-climáticas. Tanto as madeiras tratadas como as não tratadas apresentaram variação relevante quanto ao desempenho em relação ao campo de ensaio. Isso evidencia a necessidade da realização dos ensaios de durabilidade natural e eficiência de preservantes em diferentes campos de apodrecimento.

\subsection{Fungos deterioradores da madeira}

Fungos são organismos multicelulares e eucarionticos. Podem atuar como patógenos de animais e plantas, como simbiontes ou saprófitas, sendo os principais agentes na deterioração da madeira os fungos saprófitas (Zabel, 1992). Os deterioradores da madeira são, geralmente, divididos em dois grandes grupos: os fungos que possuem capacidade de degradar a parede celular e os fungos que utilizam apenas substâncias de reserva (açúcares e amido) presentes no lume celular.

Os fungos que não causam a degradação enzimática na parede celular são conhecidos como fungos manchadores e emboloradores. Pertencem as subdivisões Ascomycotina e dos fungos mitospóricos, e têm importante papel no processo de sucessão microbiológica da madeira em contato com o solo ou submersa. Utilizam substâncias de reserva da madeira como alimento, afetando sua permeabilidade (Eaton, 1993).

Quando atuam na deterioração da madeira, os fungos têm um importante papel ecológico na reciclagem de nutrientes para o solo (Oliveira et al., 1986). Isto é possível, pois esses organismos são os principais agentes decompositores dos componentes primários da madeira, que são a celulose, a hemicelulose e a lignina (Alexoupoulos, 1996). 
Os fungos são responsáveis pela destruição de uma grande variedade de produtos a base de madeira como postes, dormentes, cercas, etc, causando grandes prejuízos econômicos.

A madeira só se torna susceptível ao ataque por fungos quando encontra-se com $20 \%$ ou mais de umidade (Eaton, 1993). Ao menos que esteja protegida da umidade ou tratada com preservantes, a madeira será atacada por fungos apodrecedores (Alexoupoulos, 1996).

Os fungos capazes de promover a degradação enzimática das paredes celulares são divididos em três grupos: fungos de podridão mole, fungos de podridão parda e fungos de podridão branca (Oliveira et al.,1986).

A principal subdivisão em podridão branca e parda foi feita em 1874 por Harting, baseada na coloração da madeira residual; assumindo o material esbranquiçado (celulose) como podridão branca e o material acastanhado (lignina) como podridão parda (Zabel,1992).

A podridão parda é causada por fungos pertencentes à subdivisão Basidiomycota, que em geral apresentam alta capacidade de degradação (Oliveira et al.,1986).

Segundo Nilsson (1988), estes fungos despolimerizam a celulose, sendo a lignina pouco afetada. A madeira colonizada por fungos de podridão parda apresenta coloração marrom escura e em estágios avançados de apodrecimento, ocorre craqueamento cuboidal (Eaton, 1993).

Segundo Anagnost (1998), a principal característica observada sob microscopia de luz nas madeiras de coníferas deterioradas por podridão parda é a presença de orifícios nas paredes celulares do parênquima radial, desde o início do processo. Na secção transversal, as células de lenho inicial perdem a forma e, em estágios avançados de deterioração, a parede celular aparece mais fina do que na madeira sadia.

A podridão branca, assim como a podridão parda, é causada por fungos pertencentes à subdivisão dos Basidiomycota, com alta capacidade de degradação. Porém, neste caso a lignina é removida da parede da célula, 
sendo a celulose e a hemicelulose degradadas em proporções variadas, dependendo da espécie de fungo envolvida (Oliveira et al.,1986). A madeira apodrecida apresenta-se mais clara e macia do que a sadia.

Segundo Eaton (1993), nos estágios iniciais de deterioração, as áreas apodrecidas podem ser delimitadas por linhas escuras. Oliveira et al. (1986), citam a existência de um tipo de ataque, onde pequenas áreas apodrecidas encontram-se intermeadas por áreas sadias. Nesses casos o apodrecimento recebe o nome de "podridão branca em bolsas".

A madeira deteriorada por estes fungos tem suas propriedades físicas e mecânicas afetadas, havendo diminuição na resistência e aumento da permeabilidade (Oliveira et al.,1986).

A madeira atacada por fungos de podridão mole apresenta a camada superficial escurecida e com pequenas fissuras paralelas e perpendiculares a grã (Oliveira et al., 1986). Este ataque foi descrito por Savory em 1954, sendo caracterizado macroscopicamente pela superfície amolecida e microscopicamente pelo ataque seletivo no interior da parede secundária da célula (Zabel, 1992).

Brazolin (1997), afirma que atualmente é aceita a definição proposta por Nilsson (s.d), que considera a podridão mole como uma forma de apodrecimento causada por fungos pertencentes as subdivisões Ascomycotina e as dos fungos mitospóricos. Em geral, são considerados microrganismos com capacidade limitada de degradação, desenvolvendo-se dentro das paredes celulares e decompondo seus principais componentes como a celulose e hemicelulose (Oliveira et al.,1986).

A velocidade de degradação da lignina depende da espécie de fungo e da madeira atacada (Nilsson, s.d). Também há uma redução marcante nas características mecânicas de uma peça intensamente deteriorada por fungos de podridão mole. Por ser geralmente um ataque superficial, sua importância está relacionada com a secção transversal da peça. Em postes, 
observam-se consideráveis reduções na resistência à flexão na região de afloramento.

Rayner \& Boddy (1988), citam a ocorrência de deterioração por fungos de podridão mole em madeiras tratadas com CCA (arsenato de cobre cromatado). Eaton (1993), afirma que na madeira tratada com CCA o principal grupo de agentes deterioradores são os fungos de podridão mole. Drysdale (1984), cita a ocorrência de podridão parda, podridão mole e ataques por bactérias em postes de madeiras do gênero Pinus tratados com CCA.

Segundo Nicholas (1985), geralmente os fungos tolerantes ao cobre são susceptíveis ao arsênio e vice-versa. No entanto, várias espécies de fungos de podridão mole são resistentes a altas concentrações de preservantes (especialmente os salinos), e outras são capazes de detoxificar os preservantes (Oliveira et al.,1986).

\subsection{Insetos xilófagos}

A madeira está sujeita a deterioração por insetos, desde a árvore viva até a madeira em serviço. As principais ordens encontradas deteriorando o material madeira são a Isoptera (cupins), a Coleoptera (brocas) e, com menor importância, a Hymenoptera (vespas e formigas) (Eaton, 1993).

Os insetos pertencentes à ordem Coleoptera são mastigadores e muitas espécies são xilófagas. A família Cerambycidae possui espécies que atacam desde a árvore viva até madeira em decomposição. As espécies da família Scolytidae e Platypodidae atacam exclusivamente a árvore viva ou recém abatida; a família Bostrychidae ataca madeiras em processo de secagem enquanto as famílias Lyctidae e Anobiidae atacam apenas a madeira já seca (Oliveira et al.,1986).

Os cupins ou térmitas são insetos eussociais pertencentes à ordem Isoptera. A casta típica da ordem é o reprodutor alado, que após a revoada perde suas asas, forma o casal e instala uma nova colônia. Esta colônia apresenta duas castas: a dos soldados e a dos operários. Estes não 
possuem asas e são responsáveis pela manutenção da colônia e cuidados com a prole. São insetos mastigadores e tem como principal alimento a celulose que pode vir de uma grande variedade de produtos. A madeira, por ser um material com alto teor de celulose, é o alimento preferido por um grande número de espécies de cupins (Oliveira et al.,1986).

Os cupins são considerados os insetos causadores dos maiores danos econômicos. Considerando os prejuízos causados por cupins apenas no meio urbano, Edwards \& Mill (1986), estimaram que são gastos no mundo todo, mais de 2 bilhões de dólares em tratamentos curativos de edificações. No Brasil, Lelis (1994), estima que, apenas na cidade de São Paulo foram gastos 3,3 milhões de dólares no tratamento de 240 edificações. No entanto, a maioria das espécies de cupins não causa qualquer prejuízo à humanidade, ao contrário, são importantes agentes de degradação de madeira e compostos celulósicos, implicados na ciclagem de nutrientes nos ecossistemas (Fontes, 1995).

Lepsch (1977), cita a importância dos cupins na movimentação de materiais no solo por estarem constantemente triturando restos vegetais e cavando galerias, o que contribui para a formação do húmus e manutenção da porosidade e areação do solo.

Nas Américas, estima-se a ocorrência de aproximadamente 550 espécies sendo que cerca de 200 espécies ocorrem no Brasil (Fontes, 1998). Segundo Lelis (2000), há no mundo atualmente cerca de 2.500 espécies descritas e apenas 10\% delas são consideradas pragas. As espécies de ocorrência no Brasil estão distribuídas em 4 famílias, Kalotermitidae, Rhinotermitidae, Serritermitidae e Termitidae (Junqueira, 1999).

A família Kalotermitidae é constituída por espécies que constroem suas galerias e ninhos exclusivamente dentro da madeira da qual se alimentam, formando colônias não elaboradas e pouco populosas (alguns milhares de indivíduos) (Oliveira et al., 1986). Esta família ocorre na região Neotropical e seus indivíduos atacam a madeira seca. Suas colônias não 
possuem operários e o trabalho é feito pelos jovens (Berti Filho, 1993). A principal característica dos soldados desta família é a cabeça comprida e as mandíbulas denteadas. Os principais gêneros que ocorrem no Brasil são Cryptotermes, Neotermes e Rugitermes.

Os térmitas pertencentes à família Rhinotermitidae constroem ninhos subterrâneos, que podem estar em conexão com a madeira, ou ninhos fora do solo, construídos na madeira do tronco das árvores (Berti Filho, 1993). Os insetos desta família possuem protozoários simbiontes no intestino e infestam preferencialmente a madeira já degradada por fungos ou bactérias e com umidade constante (Richardson, 1993). As principais subfamílias são: Coptotermitinae (gênero Coptotermes) e Heterotermitinae (gênero Heterotermes). A família Termitidae é a que possui maior número de espécies, as colônias mais populosas e os ninhos com arquitetura mais elaborada, podendo ser subterrâneos, arborícolas ou semi-arborícolas (Oliveira et al.,1986). Possui quatro subfamílias: Armitermitinae, Macrotermitinae, Nasutitermitinae e Termitinae.

O mesmo autor cita ainda, os gêneros Coptotermes, Heterotermes e Nasutitermes como os principais que nidificam no solo ou em contato e freqüentemente atacam madeiras tanto secas quanto úmidas.

Segundo Cavalcante (1982b), as espécies Cryptotermes brevis, Coptotermes havilandi e Heterotermes sp. são as mais importantes, atacando construções, enquanto que os gêneros Nasutitermes e Cornitermes são mais freqüentes no ataque a madeiras ao ar livre.

A espécie Heterotermes tenuis, da família Rhinotermitidae, é nativa do Brasil, sendo encontrada tanto em centros urbanos quanto em áreas rurais (Costa, 2000). Vive em madeiras processadas que apresentem umidade, além de cercas e pedaços de madeira no solo (Berti Filho, 1993).

Segundo Lelis (2000), os prejuízos decorrentes do ataque desses insetos devem-se principalmente ao uso inadequado da madeira e não a este material em si. Os usuários da madeira conhecem as vantagens desse 
material, mas desconhecem ou negligenciam aspectos importantes da sua deterioração biológica. Por essa razão, não são tomadas medidas preventivas que seriam fundamentais para aumentar a vida útil da madeira e, consequentemente, reduzir os prejuízos advindos da sua deterioração. $\mathrm{O}$ mesmo autor aponta a região Sudeste, especialmente no eixo São Paulo - Rio de Janeiro, como o foco dos principais problemas de cupins no Brasil. Porém, os problemas encontrados nessa região não representam a realidade do país, pois a presença e a freqüência das espécies de cupim variam de região para região.

\subsection{Deterioradores identificados em campos de apodrecimento}

Na Tabela 5 estão citados os gêneros de cupins coletados em campos de apodrecimento de diversas localidades.

Tabela 5. Gêneros de cupins coletados em campos de apodrecimento.

\begin{tabular}{|c|c|c|c|}
\hline Localização & Família & Gênero & Referência \\
\hline Mogi-Guaçu SP. & Termitidae & $\begin{array}{l}\text { Procornitermes } \\
\text { Cornitermes }\end{array}$ & $\begin{array}{c}\text { Lepage \& Montagna, } \\
1973\end{array}$ \\
\hline \multirow[t]{2}{*}{ Mogi-Guaçu SP. } & Rhinotermitidae & $\begin{array}{l}\text { Heterotermes } \\
\text { Constrictotermes } \\
\text { Armitermes }\end{array}$ & $\begin{array}{l}\text { Cavalcante \& Lelis, } \\
1974\end{array}$ \\
\hline & Kalotermitidae & Rugitermes & \\
\hline Luiz Antônio - SP & $\begin{array}{l}\text { Rhinotermitidae } \\
\text { Termitidae }\end{array}$ & $\begin{array}{l}\text { Heterotermes } \\
\text { Nasutitermes }\end{array}$ & $\begin{array}{l}\text { Lepage \& Montagna, } \\
\qquad 1973\end{array}$ \\
\hline Suriname & Termitidae & Nasutitermes & Van Acker et al., 2000 \\
\hline \multirow[t]{2}{*}{ Manaus AM } & Rhinotermitidae & $\begin{array}{l}\text { Heterotermes } \\
\text { Coptotermes }\end{array}$ & Jesus et al., 1998 \\
\hline & Termitidae & $\begin{array}{l}\text { Anoplotermes } \\
\text { Nasutitermes }\end{array}$ & \\
\hline
\end{tabular}


Os organismos identificados por Lepage \& Montagna (1973), foram coletados após um ano de instalação dos campos de apodrecimento nas Estações experimentais de Mogi-Guaçu e Luiz Antônio, em moirões de Eucalyptus saligna tratados. Os gêneros de cupins identificados por Cavalcante \& Lelis (1974), foram coletados no mesmo campo da Estação Experimental de Mogi-Guaçu, após 4 anos da data de instalação.

$\mathrm{Na}$ Tabela 6 estão citadas as espécies de fungos e os tipos de deterioração encontrados em campos de apodrecimento.

Tabela 6. Espécies de fungos coletadas em campos de apodrecimento.

\begin{tabular}{|c|c|c|}
\hline Localização & $\begin{array}{l}\text { Espécie de fungo ou } \\
\text { tipo de deterioração }\end{array}$ & Referência \\
\hline \multirow[t]{6}{*}{ Mogi-Guaçu - SP } & Lentinus crinitus & $\begin{array}{l}\text { Cavalcante \& Lelis, } \\
1974\end{array}$ \\
\hline & Pycnoporus sanguineus & \\
\hline & Trametes rigida & \\
\hline & Gloeophyllum striatum & \\
\hline & Poria sp. & \\
\hline & Polyporus occidentalis & \\
\hline Nova Zelândia & Podridão mole e parda & Hedley et al., 2000 \\
\hline \multirow[t]{6}{*}{ Manaus } & Calocera cornea & Jesus et al., 1998 \\
\hline & Cerioporia xylostromatoides & \\
\hline & Dacryopinax spathularia & \\
\hline & Herpotricha schiedermayeriana & \\
\hline & Rigidoporus lineatus & \\
\hline & Trametes modesta & \\
\hline
\end{tabular}


Segundo Cavalcante (1982b), os fungos dos gêneros Polyporus e Schizophyllum são os de maior distribuição no Brasil. Reis (1965), considera o ataque dos fungos de podridão branca e podridão mole a causa da maioria das destruições na madeira de Pinus silvestris sem tratamento.

Jesus et al. (1998), estudando a durabilidade natural de madeiras da Amazônia, observaram diferenças no tipo de deterioração em relação às espécies. Em algumas espécies de madeira, tanto os fungos como os térmitas participaram efetivamente na degradação, porém os fungos foram responsáveis pelo maior nível de degradação. Outras madeiras obtiveram o mesmo nível de degradação em decorrência da infestação por térmitas, e outras mostraram especificidade à deterioração por fungos. Este mesmo trabalho indicou entre 0 e 5 anos a vida útil das espécies infestadas por térmitas, enquanto as madeiras colonizadas por fungos apresentaram maior vida útil. A provável explicação é que o processo de colonização por fungos é mais lento em relação aos térmitas, além da diferença no potencial lignocelulolítico destes organismos. 


\section{MATERIAL E MÉTODOS}

\subsection{Histórico do experimento}

O campo de apodrecimento avaliado neste trabalho foi instalado em 1980, como parte de um projeto de pesquisa envolvendo o Departamento de Ciências Florestais da Escola Superior de Agricultura "Luiz de Queiroz" (ESALQ / USP) e o Instituto Florestal do Estado de São Paulo, cujo objetivo principal era avaliar a durabilidade da madeira do gênero Pinus submetida a tratamento preservante.

O método de ensaio adotado foi o "Método Padrão sugerido pela IUFRO (International Union of Forestry Research Organizations) para Ensaios de Campo com Estacas de Madeira", descrito por Lepage (1970). Neste método, são utilizadas estacas de $25 \mathrm{~mm}$ X $50 \mathrm{~mm} \times 500 \mathrm{~mm}$, com a última dimensão paralela à fibra, livre de nós, fendas, manchas, apodrecimento, orifícios de insetos e outros defeitos.

O ensaio totalizou 100 tratamentos, combinando quatro espécies de Pinus, cinco produtos preservantes e cinco níveis de retenção. As espécies utilizadas foram o Pinus elliottii Engl. var. elliottii, o Pinus caribaea Mor. var. hondurensis, B \& G., o Pinus oocarpa Shied e o Pinus kesiya Royle ex Gordon, oriundas de plantios da Estação Experimental de Itirapina, com aproximadamente 14 anos de idade na época. 
Os produtos preservantes utilizados foram o arsenato de cobre cromatado tipo $A$, tipo $B$ e tipo $C$ (CCA-A, CCA-B, CCA-C), o borato de cobre cromatado (CCB) e o pentaclorofenol dissolvido em óleo diesel. A composição dos produtos utilizados consta na Tabela 7 .

Tabela 7. Composição quantitativa dos ingredientes ativos nos produtos preservantes utilizados.

\begin{tabular}{lccc}
\hline \multicolumn{1}{c}{ Produto } & \multicolumn{3}{c}{ Proporção dos ingredientes ativos (\%) } \\
\hline CCA tipo A & $66,5 \mathrm{CrO}_{3}$ & $18,1 \mathrm{CuO}$ & $16,4 \mathrm{As}_{2} \mathrm{O}_{5}$ \\
CCA tipo B & $35,3 \mathrm{CrO}_{3}$ & $19,6 \mathrm{CuO}$ & $45,1 \mathrm{As}_{2} \mathrm{O}_{5}$ \\
CCA tipo C & $45,5 \mathrm{CrO}_{3}$ & $18,5 \mathrm{CuO}$ & $34,0 \mathrm{As}_{2} \mathrm{O}_{5}$ \\
CCB & $63,5 \mathrm{CrO}_{3}$ & $26,0 \mathrm{CuO}$ & $10,5 \mathrm{~B}$ \\
Pentaclorofenol & $85,0 \mathrm{C}_{6} \mathrm{Cl}_{5} \mathrm{OH}$ & & \\
\hline
\end{tabular}

Para os hidrossolúveis, o tratamento das madeiras foi feito sob pressão pelo método BETHEL (célula-cheia) e para o pentaclorofenol pelo método LOWRY (célula-vazia). Os níveis de retenção efetiva são descritos na Tabela 8. Segundo Jankowsky ${ }^{1}$, o cálculo das retenções iniciais (kg de ingrediente ativo do produto $/ \mathrm{m}^{3}$ de madeira) foi determinado pela diferença de massa das estacas. A estaca era individualmente pesada antes e após o tratamento, considerando que a diferença de massa correspondia ao volume de solução retido pela estaca. Conhecendo-se a densidade relativa e a concentração da solução de tratamento era calculada a retenção, admitindo-se que o volume das estacas era constante e igual para todas.

1 JANKWOSKY, I. P. (ESALQ. Depto. de Ciências Florestais) Comunicação pessoal, 2001 
Tabela 8. Retenções efetivas $\left(\mathrm{kg} / \mathrm{m}^{3}\right)$ das estacas instaladas em Mogi-Guaçu $\left({ }^{*}\right)$.

\begin{tabular}{|c|c|c|c|c|c|}
\hline \multirow[b]{2}{*}{ Produto } & \multirow[b]{2}{*}{ N.R.** } & \multicolumn{4}{|c|}{ Espécies } \\
\hline & & P. kesyia & P.oocarpa & P.elliottii & P. c. hondurensis \\
\hline \multirow{5}{*}{ CCA tipo A } & $\mathrm{R} 1$ & 5,22 & 4,75 & 4,40 & 5,26 \\
\hline & $\mathrm{R} 2$ & 6,78 & 6,59 & 5,73 & 6,17 \\
\hline & R3 & 8,23 & 6,59 & 6,62 & 7,88 \\
\hline & $\mathrm{R} 4$ & 10,60 & 7,73 & 9,16 & 10,45 \\
\hline & R5 & 12,77 & 9,86 & 10,53 & 12,80 \\
\hline \multirow{5}{*}{ CCA tipo B } & $\mathrm{R} 1$ & 4,87 & 4,63 & 4,61 & 4,05 \\
\hline & $\mathrm{R} 2$ & 6,81 & 6,38 & 5,14 & 5,99 \\
\hline & R3 & 7,02 & 6,42 & 6,40 & 7,52 \\
\hline & $\mathrm{R} 4$ & 8,54 & 8,74 & 7,33 & 8,86 \\
\hline & R5 & 9,58 & 9,29 & 9,23 & 11,63 \\
\hline \multirow{5}{*}{ CCA tipo $\mathrm{C}$} & $\mathrm{R} 1$ & 5,31 & 5,08 & 4,72 & 4,88 \\
\hline & $\mathrm{R} 2$ & 5,70 & 5,44 & 5,61 & 6,44 \\
\hline & R3 & 6,28 & 6,14 & 6,76 & 7,15 \\
\hline & $\mathrm{R} 4$ & 8,75 & 8,59 & 7,37 & 8,19 \\
\hline & R5 & 7,85 & 7,58 & 7,11 & 7,55 \\
\hline \multirow{5}{*}{ CCB } & $\mathrm{R} 1$ & 4,42 & 4,41 & 4,08 & 4,58 \\
\hline & $\mathrm{R} 2$ & 5,79 & 6,08 & 5,54 & 6,18 \\
\hline & R3 & 8,84 & 8,00 & 7,33 & 8,22 \\
\hline & $\mathrm{R} 4$ & 9,87 & 9,38 & 7,81 & 8,88 \\
\hline & R5 & 10,43 & 4,42 & 9,75 & 10,60 \\
\hline \multirow{5}{*}{ Pentaclorofenol } & $\mathrm{R} 1$ & 4,30 & 2,99 & 4,25 & 4,00 \\
\hline & $\mathrm{R} 2$ & 4,91 & 4,46 & 4,08 & 4,04 \\
\hline & R3 & 5,13 & 4,58 & 5,77 & 6,85 \\
\hline & R4 & 10,71 & 10,15 & 8,51 & 10,30 \\
\hline & R5 & 14,10 & 13,05 & 12,20 & 14,52 \\
\hline
\end{tabular}

$\left({ }^{*}\right)$ - valores médios para as dez estacas de cada tratamento, aferidos por diferença de massa.

$\left.{ }^{* *}\right)$ - nível de retenção.

Fonte: Fernandes et al. (1990). 
A Estação Experimental de Mogi-Guaçu está localizada a 22 $2^{\circ} 18^{\prime}$ de Latitude Sul e 47013' de Longitude Oeste Gr., a $600 \mathrm{~m}$ de altitude acima do nível do mar. Segundo a classificação de Köeppen, o solo é do tipo Lva e clima Cwa. A vegetação original da região é o cerrado típico.

O campo foi instalado em 25 de agosto de 1980. Foram instaladas 1040 estacas, seguindo um delineamento de blocos casualizados com 10 repetições. As estacas foram enterradas até aproximadamente metade de seu comprimento, sendo o espaçamento entre elas de $50 \mathrm{~cm}$, e entre as fileiras (blocos) de $100 \mathrm{~cm}$ (Figura 1).

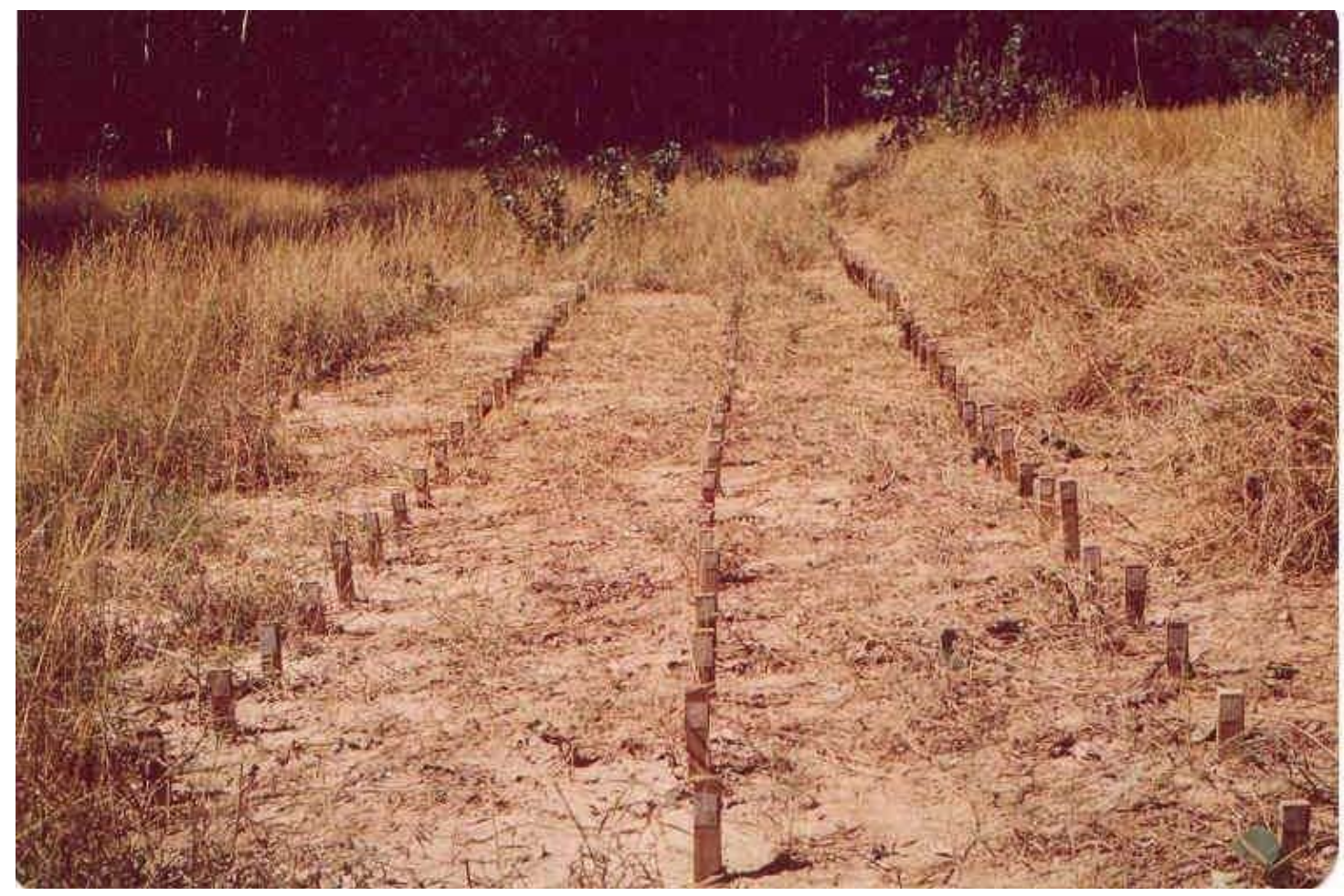

Figura 1 - Aspecto do campo de apodrecimento de Mogi-Guaçu, em 1990.

As avaliações foram realizadas 6, 23 e 111 meses após a data de instalação. Os resultados da avaliação realizada aos 111 meses foram divulgados por Fernandes et al. (1990), e encontram-se na Tabela 9. 
Tabela 9. Estado de sanidade das estacas no campo de Mogi - Guaçu, decorridos 111 meses de instalação.

\begin{tabular}{|c|c|c|c|c|c|}
\hline \multirow[b]{2}{*}{ Produto } & \multirow[b]{2}{*}{ N.R. ${ }^{*}$} & \multicolumn{4}{|c|}{ Índice de Comportamento } \\
\hline & & P. kesiya & P. oocarpa & P. elliottii & P. c. hondurensis \\
\hline \multirow{5}{*}{ CCA tipo A } & R1 & 99,0 & 98,7 & 97,7 & 97,7 \\
\hline & $\mathrm{R} 2$ & 99,0 & 99,0 & 99,0 & 99,0 \\
\hline & R3 & 99,0 & 100,0 & 98,0 & 100,0 \\
\hline & R4 & 99,8 & 99,0 & 100,0 & 100,0 \\
\hline & R5 & 97,7 & 100,0 & 99,0 & 98,0 \\
\hline \multirow{5}{*}{ CCA tipo B } & R1 & 100,0 & 100,0 & 100,0 & 100,0 \\
\hline & R2 & 100,0 & 99,0 & 100,0 & 100,0 \\
\hline & R3 & 100,0 & 100,0 & 100,0 & 100,0 \\
\hline & R4 & 100,0 & 100,0 & 98,0 & 100,0 \\
\hline & R5 & 100,0 & 100,0 & 98,8 & 100,0 \\
\hline \multirow{5}{*}{ CCA tipo C } & $\mathrm{R} 1$ & 100,0 & 100,0 & 98,0 & 100,0 \\
\hline & $\mathrm{R} 2$ & 100,0 & 100,0 & 99,0 & 100,0 \\
\hline & R3 & 99,0 & 100,0 & 98,0 & 100,0 \\
\hline & R4 & 100,0 & 98,7 & 100,0 & 100,0 \\
\hline & R5 & 100,0 & 100,0 & 100,0 & 100,0 \\
\hline \multirow{5}{*}{ CCB } & R1 & 94,0 & 93,0 & 96,0 & 97,0 \\
\hline & $\mathrm{R} 2$ & 87,0 & 93,0 & 91,0 & 94,0 \\
\hline & R3 & 98,0 & 92,0 & 95,0 & 97,0 \\
\hline & R4 & 93,0 & 92,0 & 96,0 & 97,0 \\
\hline & R5 & 95,0 & 97,0 & 96,0 & 97,0 \\
\hline \multirow{5}{*}{$\begin{array}{l}\text { Pentacloro- } \\
\text { fenol }\end{array}$} & R1 & 71,0 & 81,1 & 86,2 & 81,0 \\
\hline & $\mathrm{R} 2$ & 77,8 & 82,0 & 84,4 & 84,4 \\
\hline & R3 & 81,0 & 78,8 & 80,0 & 89,0 \\
\hline & R4 & 84,0 & 90,0 & 84,0 & 84,0 \\
\hline & R5 & 76,0 & 93,0 & 80,0 & 94,0 \\
\hline Média & & 94,0 & 95,45 & 95,04 & 96,66 \\
\hline
\end{tabular}

(*) N.R. - nível de retenção,

Fonte: Fernandes et al. (1990). 
Os autores concluíram que:

- a madeira de Pinus sem tratamento preservante apresenta vida média inferior a um ano;

- nos tratamentos com preservantes hidrossolúveis, o nível de retenção dos produtos não influenciou nos índices de comportamento observados até a data da inspeção;

- os produtos com teor mais elevado de componentes inseticidas proporcionaram um melhor desempenho;

- o desempenho da madeira de Pinus tratada com preservantes não sofreu interferências da espécie até a data da inspeção.

A fim de verificar a atividade biológica do solo, em janeiro do ano de 2001 foram instaladas 16 testemunhas adicionais (estacas sem tratamento preservante). As estacas testemunhas foram confeccionadas na serraria da ESALQ, com madeira da espécie Pinus oocarpa, nas mesmas dimensões das peças do ensaio em andamento (25mm X 50mm X 500mm).

A avaliação do estado de sanidade das testemunhas do campo de Mogi-Guaçu foi realizada após 7 meses da data de instalação.

\subsection{Avaliação da durabilidade}

Após 252 meses de instalação do campo de Mogi-Guaçu, avaliou-se a durabilidade das estacas segundo o mesmo método utilizado nas inspeções anteriores. A Figura 2 mostra o aspecto do campo na data da avaliação. 


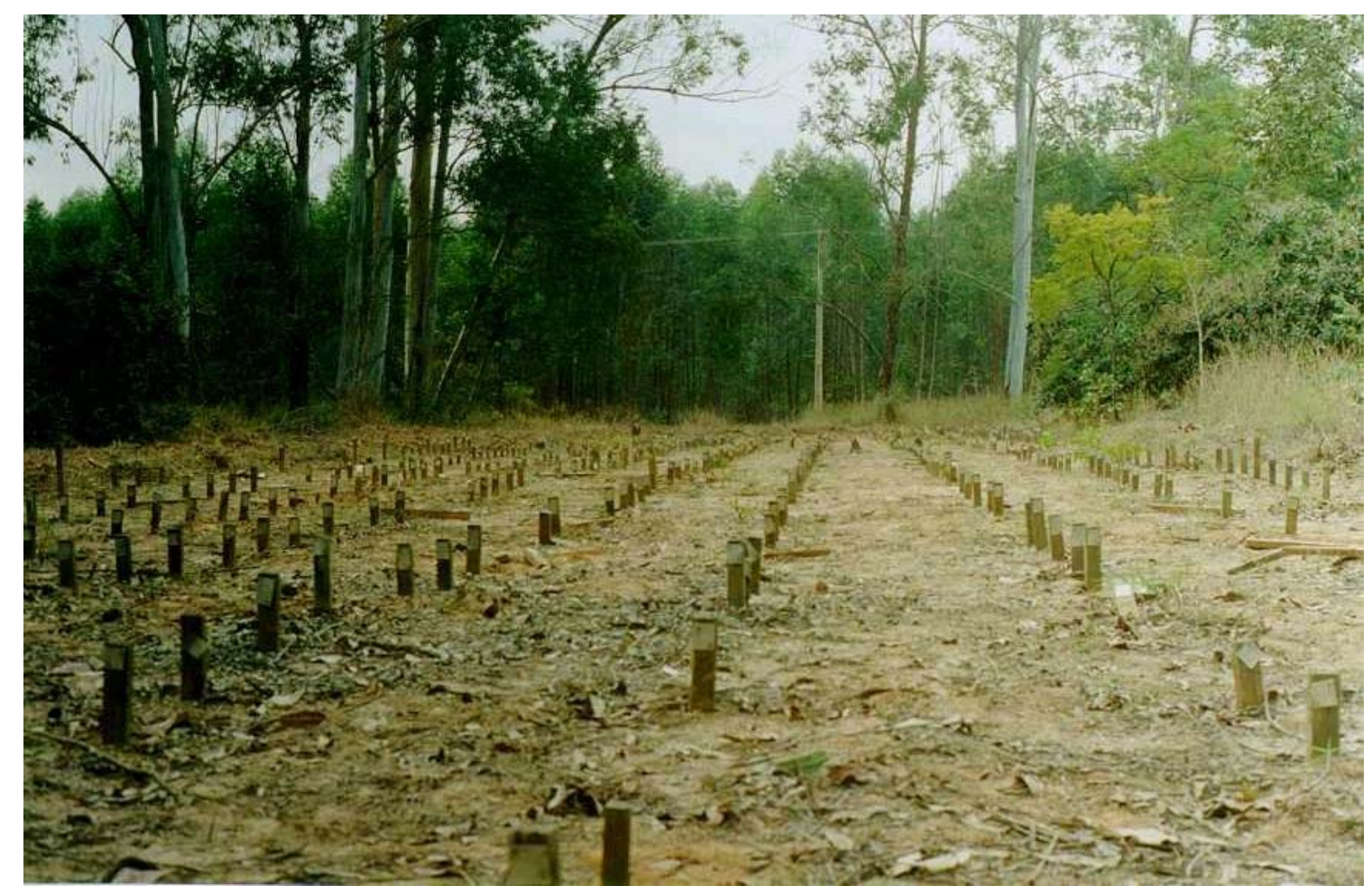

Figura 2 - Campo de apodrecimento de Mogi-Guaçu, em 2001.

A primeira parte da inspeção consistiu em submeter as peças, ainda fincadas no solo, a impacto leve e perpendicular à parte exposta de uma das faces; verificando se houve perda de resistência suficiente para permitir a quebra da estaca. As peças que não apresentaram ruptura foram removidas do solo, limpas e examinadas macroscopicamente com o auxílio de uma sovela. $O$ padrão de notas atribuído foi baseado no aspecto das estacas (Figura 3) seguindo o critério de avaliação descrito por Lepage (1970) (Tabela 10). 


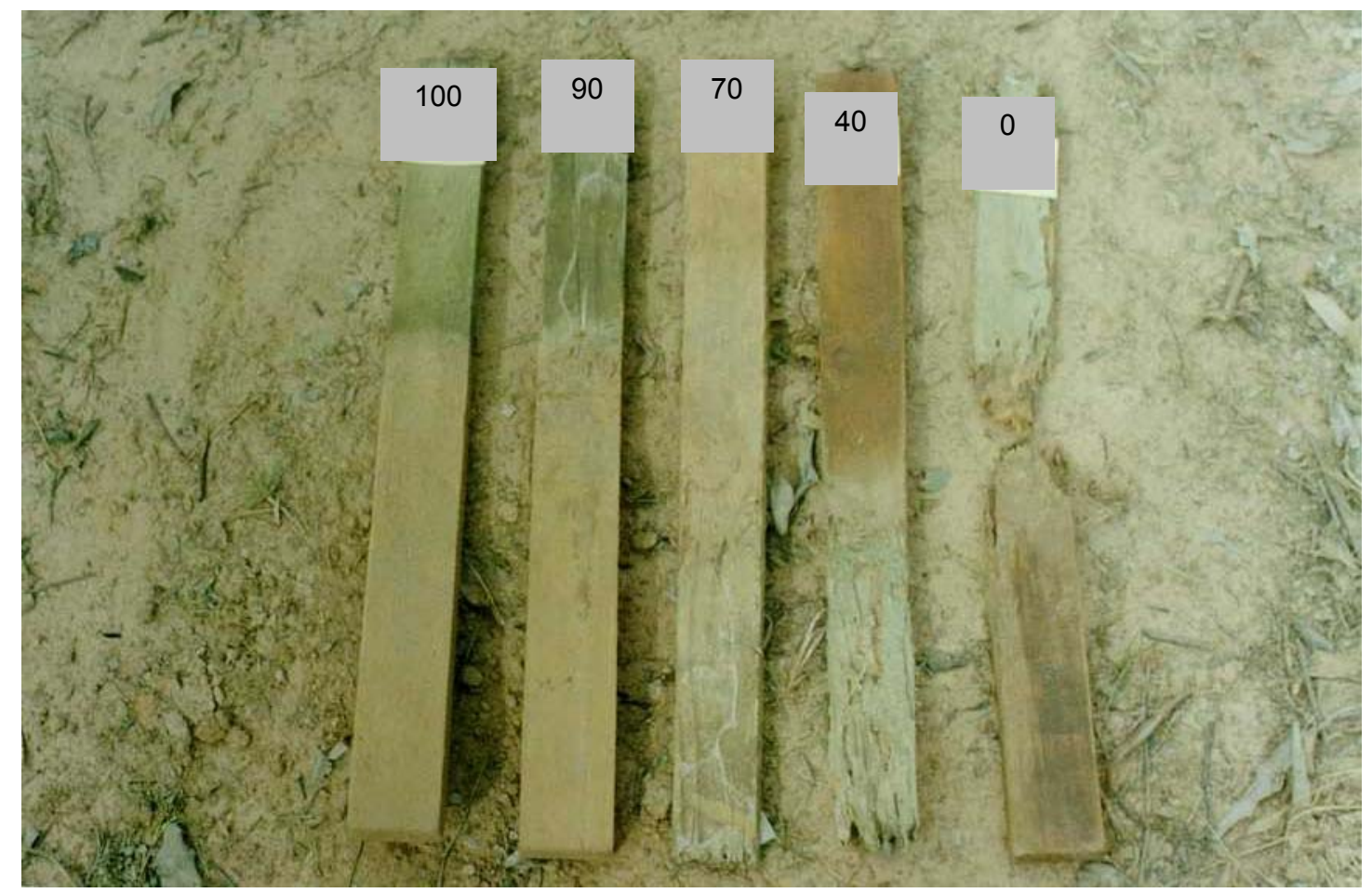

Figura 3 - Aspecto das estacas segundo Índice de Comportamento (I.C.).

Tabela 10. Critério de avaliação do estado de sanidade (Lepage, 1970).

Estado de Sanidade Índice de Comportamento

Sadio - nenhum ataque 100

Ataque leve ou superficial de fungos ou de térmitas 90

Ataque evidente mas moderado de fungos ou térmitas 70

Apodrecimento intenso ou ataque interno de térmitas 40

Quebra / perda quase total de resistência

0

A gradação do ataque de térmitas e fungos foi relatada separadamente, e o aspecto macroscópico das peças foi analisado a fim de identificar o tipo de apodrecimento. A vida média dos tratamentos que apresentaram falhas foi estimada com base na curva de McLean (Lepage, 1986). 


\subsection{Confirmação da sanidade biológica}

A fim de confirmar o ataque por fungos apodrecedores, foram coletadas amostras em campo e preparadas em laboratório de acordo com o método descrito por Cavalcante (1982a). Dessas amostras foram obtidos cortes histológicos em micrótomo de deslize, a seguir corados com solução de safranina $1 \%$ (cora tecidos lignificados), lavados em água destilada, corados com picronilina azul (cora hifas de fungos e celulose), lavados em água destilada, em série alcóolica de 30 a 100\% e em xilol. Após a coração foram montados em lâminas com Bálsamo do Canadá.

A análise foi efetuada em microscópio de luz comum e de luz polarizada, buscando confirmar a presença de hifas (fungos xilófagos em geral) e cavidades na parede celular (típicas de fungos de podridão mole).

Em relação aos cupins foram coletados indivíduos diretamente das estacas e do solo ao redor das mesmas, mantidos em álcool $70 \%$ e posteriormente encaminhados para identificação no laboratório de Entomologia Florestal do Departamento de Entomologia, Fitopatologia e Zoologia Agrícola da Escola Superior de Agricultura 'Luiz de Queiroz". As identificações foram realizadas segundo a chave ilustrada de Constantino (1999).

\subsection{Delineamento estatístico}

Para a análise estatística adotou-se o delineamento em blocos casualizados, com arranjo fatorial, (4X5X4), englobando os seguintes fatores:

- 04 espécies (Pinus elliottii Engl. var. elliottii, Pinus caribaea Mor. var. hondurensis, B \& G., Pinus oocarpa Shied e Pinus kesiya Royle ex Gordon);

- 04 produto (CCA-A, CCA-B, CCA-C e CCB);

- 05 níveis de retenção $\left(R 1=5 \mathrm{~kg} / \mathrm{m}^{3}, \mathrm{R} 2=6,5 \mathrm{~kg} / \mathrm{m}^{3}, \mathrm{R} 3=8 \mathrm{~kg} / \mathrm{m}^{3}, \mathrm{R} 4=\right.$ $9,5 \mathrm{~kg} / \mathrm{m}^{3}, \mathrm{R} 5=11 \mathrm{~kg} / \mathrm{m}^{3}$ ); com 9 repetições (estacas) por tratamento. 
Tabela 11. Esquema da análise da variância.

\begin{tabular}{lc}
\hline \multicolumn{1}{c}{ Causa de Variação } & Graus de Liberdade \\
\hline Espécies $(E)$ & 3 \\
Produto $(P)$ & 3 \\
Retenção $(R)$ & 4 \\
Ex P & 9 \\
ExR & 12 \\
P x R & 12 \\
Ex P x R & 36 \\
(Tratamentos) & $(79)$ \\
Resíduo & 579 \\
Total & 658 \\
\hline
\end{tabular}

Os resultados, expressos pelo Índice de Comportamento, foram inicialmente submetidos a análise de variância (Tabela 11). Para os fatores e as interações detectadas como significativas pelo teste $F$ procedeu-se a comparação entre médias adotando-se o teste de Tukey, ao nível de $5 \%$ de probabilidade. As análises estatísticas foram feitas com auxílio do programa SAS (STATISTIC ANALYSIS SYSTEM).

É importante destacar que o ensaio foi instalado com 10 repetições (blocos) por tratamento, mas ao longo do tempo muitas estacas foram perdidas. A maioria delas foi destruída por ação mecânica durante as limpezas periódicas do campo (como o bloco 11, por exemplo, que foi "roçado" por inteiro); enquanto que algumas podem ter sido destruídas por ação biológica e sem o respectivo registro na ficha de campo, devido ao longo tempo entre inspeções.

Quando possível identificar a falha mecânica, por indícios ou partes das estacas danificadas, procedia-se o registro na ficha. Caso contrário, registrava-se a ausência da estaca sem especificar a causa. Em ambas situações, a estaca em questão é considerada ausente e tratada como um dado perdido; tomando-se o devido cuidado na análise estatística (diferente número de repetições por tratamento). 


\section{RESULTADOS E DISCUSSÃO}

\subsection{Atividade biológica do campo}

Após 7 meses de exposição no campo de apodrecimento de Mogi-Guaçu, as testemunhas adicionais apresentaram índices de comportamento variando de 0 a 100, com incidência do ataque de cupins (Figura 4). Das 16 estacas instaladas, 12 sofreram ataque moderado (I.C. $=70$ ); 01 estaca falhou (I.C.= 0); 01 sofreu ataque intenso (I.C.=40); 01 ataque inicial (I.C.=90) e por fim 01 estaca sem ataque (I.C.=100). A vida-média das testemunhas adicionais, segundo curva de McLean, é inferior a dois anos. 


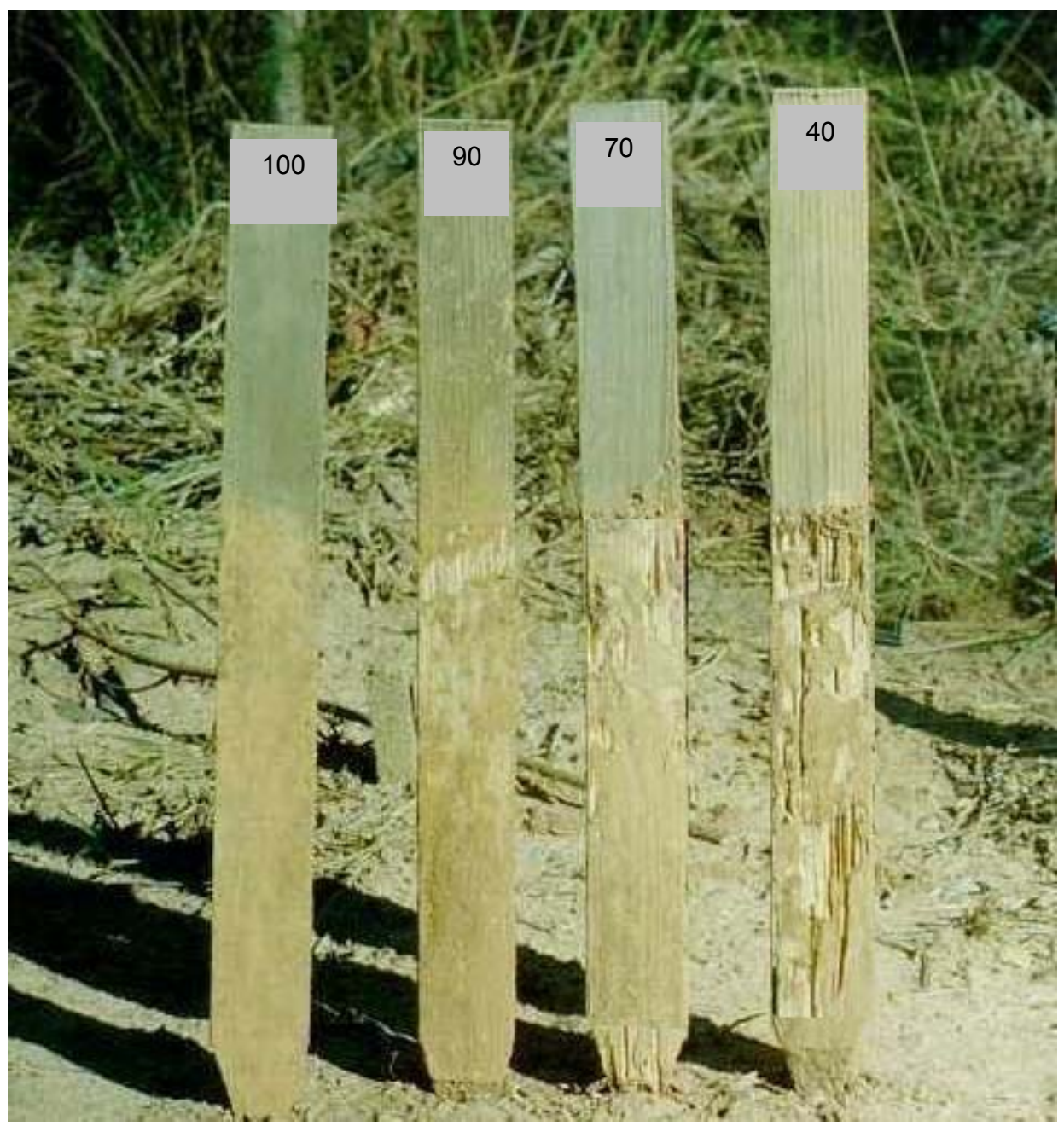

Figura 4 - Aspecto das testemunhas adicionais, segundo Índice de Comportamento.

Embora a quase totalidade das testemunhas adicionais tenha sofrido deterioração, as estacas não apresentaram aspecto macroscópico evidente do ataque por fungos apodrecedores. Este fato contradiz Lopez \& Milano (1986), que consideraram os fungos como os primeiros organismos a colonizarem a madeira em contato com o solo. Tal fato pode ser explicado pelas diferentes necessidades fisiológicas dos fungos e cupins. Uma diferença marcante é que os fungos necessitam principalmente de água na madeira para poderem utilizá-la como alimento (umidade superior a $20 \%$ ) e os gêneros de 
cupins que foram encontrados no campo (Nasutitermes sp e Heterotermes sp) não apresentam tal necessidade.

Como as estacas testemunha foram instaladas em período de seca na região (pluviosidade entre os meses de janeiro e agosto = $53,13 \mathrm{~mm} / \mathrm{mês})$, o ambiente não mostrou-se favorável para a proliferação dos fungos presentes na microflora do solo. Assim, apenas os insetos (cupins) tiveram a oportunidade de colonizar as estacas de madeira.

Mesmo não ocorrendo o ataque por fungos, a intensidade do ataque por cupins de solo comprovou que o campo de Mogi-Guaçu continua com plena atividade biológica no que se refere à deterioração de madeiras. $O$ índice médio de comportamento $(66,9)$ reforça a afirmação de diferentes autores (Jankowsky et al., 1989; Fernandes et al., 1990; Watai, 1990) quanto à reduzida durabilidade natural da madeira do gênero Pinus, geralmente inferior a dois anos quando em contato direto com o solo.

\subsection{Avaliação da durabilidade}

Os resultados da inspeção no campo de Mogi-Guaçu estão apresentados na Tabela 12, expressos pela média do Índice de Comportamento. 
Tabela 12. Valores médios do Índice de Comportamento por tratamento, após 252 meses de exposição, no campo de Mogi-Guaçu.

\begin{tabular}{|c|c|c|c|c|c|}
\hline \multirow[b]{2}{*}{ Produto } & \multirow[b]{2}{*}{ N.R. ${ }^{*}$} & \multicolumn{4}{|c|}{ Índice de Comportamento } \\
\hline & & P. kesiya & P. oocarpa & P. elliottii & P. c. hondurensis \\
\hline \multirow{5}{*}{ CCA tipo A } & R1 & 91.1 & 90.0 & 84.3 & 95.7 \\
\hline & $\mathrm{R} 2$ & 97.1 & 92.2 & 97.0 & 94.4 \\
\hline & R3 & 94.4 & 93.3 & 95.0 & 98.6 \\
\hline & R4 & 96.3 & 97.5 & 98.8 & 95.0 \\
\hline & R5 & 91.4 & 98.9 & 93.8 & 97.5 \\
\hline \multirow{5}{*}{ CCA tipo B } & $\mathrm{R} 1$ & 93.3 & 92.5 & 96.0 & 92.5 \\
\hline & $\mathrm{R} 2$ & 97.5 & 95.6 & 96.3 & 83.8 \\
\hline & R3 & 91.3 & 93.8 & 91.1 & 91.1 \\
\hline & R4 & 97.8 & 96.7 & 95.0 & 96.7 \\
\hline & R5 & 95.6 & 96.7 & 100.0 & 97.8 \\
\hline \multirow{5}{*}{ CCA tipo C } & R1 & 87.1 & 81.3 & 85.0 & 80.0 \\
\hline & $\mathrm{R} 2$ & 94.4 & 78.9 & 91.1 & 83.3 \\
\hline & R3 & 95.6 & 95.0 & 90.0 & 97.1 \\
\hline & R4 & 97.8 & 95.7 & 97.8 & 95.0 \\
\hline & R5 & 96.7 & 97.1 & 92.2 & 97.5 \\
\hline \multirow{5}{*}{ ССВ } & $\mathrm{R} 1$ & 87.5 & 91.1 & 81.1 & 90.0 \\
\hline & R2 & 76.3 & 83.3 & 75.0 & 73.8 \\
\hline & R3 & 87.8 & 93.3 & 82.2 & 88.8 \\
\hline & R4 & 73.8 & 90.0 & 90.0 & 85.0 \\
\hline & R5 & 92.2 & 94.4 & 88.8 & 91.1 \\
\hline \multirow{5}{*}{$\begin{array}{c}\text { Pentacloro- } \\
\text { Fenol }\end{array}$} & R1 & 70.0 & 91.1 & 0 & 20.0 \\
\hline & R2 & 70.0 & 83.3 & 26.7 & 80.0 \\
\hline & R3 & 24.0 & 93.3 & 30.0 & 16.0 \\
\hline & R4 & 46.0 & 90.0 & 40.0 & 32.0 \\
\hline & R5 & 31.7 & 94.4 & 20.0 & 46.0 \\
\hline
\end{tabular}

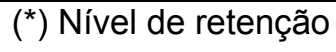


No exame da Tabela 12 destaca-se o comportamento dos tratamentos com o produto pentaclorofenol, cujas médias são notadamente inferiores. Para facilitar a análise dos tratamentos com pentaclorofenol, na Tabela 13 são comparados os resultados das inspeções aos 111 e 252 meses de exposição.

Tabela 13. Valores médios do Índice de Comportamento das estacas tratadas com pentaclorofenol, após 111 e 252 meses de exposição, no campo de Mogi-Guaçu.

\begin{tabular}{ccccccc}
\hline $\begin{array}{c}\text { Tempo } \\
\text { (meses) }\end{array}$ & N.R. ${ }^{*}$ & P. kesyia & P. oocarpa & P. elliottii & P. . hondurensis & Média \\
\hline & R1 & 71,0 & 81,1 & 86,2 & 81,0 & 79,8 \\
& R2 & 77,8 & 82,0 & 84,4 & 84,4 & 82,2 \\
\multirow{2}{*}{ 111 $^{* *}$} & R3 & 81,0 & 78,8 & 80,0 & 89,0 & 82,2 \\
& R4 & 84,0 & 90,0 & 84,0 & 84,0 & 85,5 \\
& R5 & 76,0 & 93,0 & 80,0 & 94,0 & 85,8 \\
& Média & 78,0 & 85,0 & 82,9 & 86,5 & 83,1 \\
& R1 & 70,0 & 55,0 & 0,0 & 20,0 & 36,3 \\
& R2 & 70,0 & 40,0 & 26,7 & 80,0 & 54,2 \\
& R32 & 24,0 & 24,0 & 30,0 & 16,0 & 23,5 \\
& R4 & 46,0 & 34,3 & 40,0 & 32,0 & 38,1 \\
& R5 & 31,7 & 48,6 & 20,0 & 46,0 & 36,6 \\
& Média & 48,3 & 40,4 & 23,3 & 38,8 & 37,7 \\
\hline
\end{tabular}

$\left.{ }^{*}\right)$ nível de retenção

$\left.{ }^{* *}\right)$ Fonte: Fernandes et al. (1990).

Com exceção do $P$. caribaea var hondurensis na retenção R2 $\left(4,0 \mathrm{~kg} / \mathrm{m}^{3}\right)$ e do $P$. kesyia nas retenções R1 $\left(4,3 \mathrm{~kg} / \mathrm{m}^{3}\right)$ e $R 2\left(4,9 \mathrm{~kg} / \mathrm{m}^{3}\right)$, observa-se drástica redução no Índice de Comportamento em todos os 
tratamentos com pentaclorofenol, refletindo um número excessivo de estacas ausentes (falhas) no campo, (Tabelas 19 a 22, do Apêndice).

Em virtude da falta de inspeções intermediárias, ao longo do intervalo entre a primeira (111 meses) e a segunda avaliação (252 meses), não foi possível determinar a causa exata das falhas. Estas podem ter sido a deterioração biológica ou um dano fortuito durante a limpeza periódica (capina) do campo (definida como falha mecânica).

A Figura 5 ilustra o estado de sanidade de uma estaca tratada com pentaclorofenol após 111 meses de exposição. É evidente a mancha no solo (sugerindo exsudação e escorrimento da solução de tratamento) e o início da deterioração na superfície do topo.

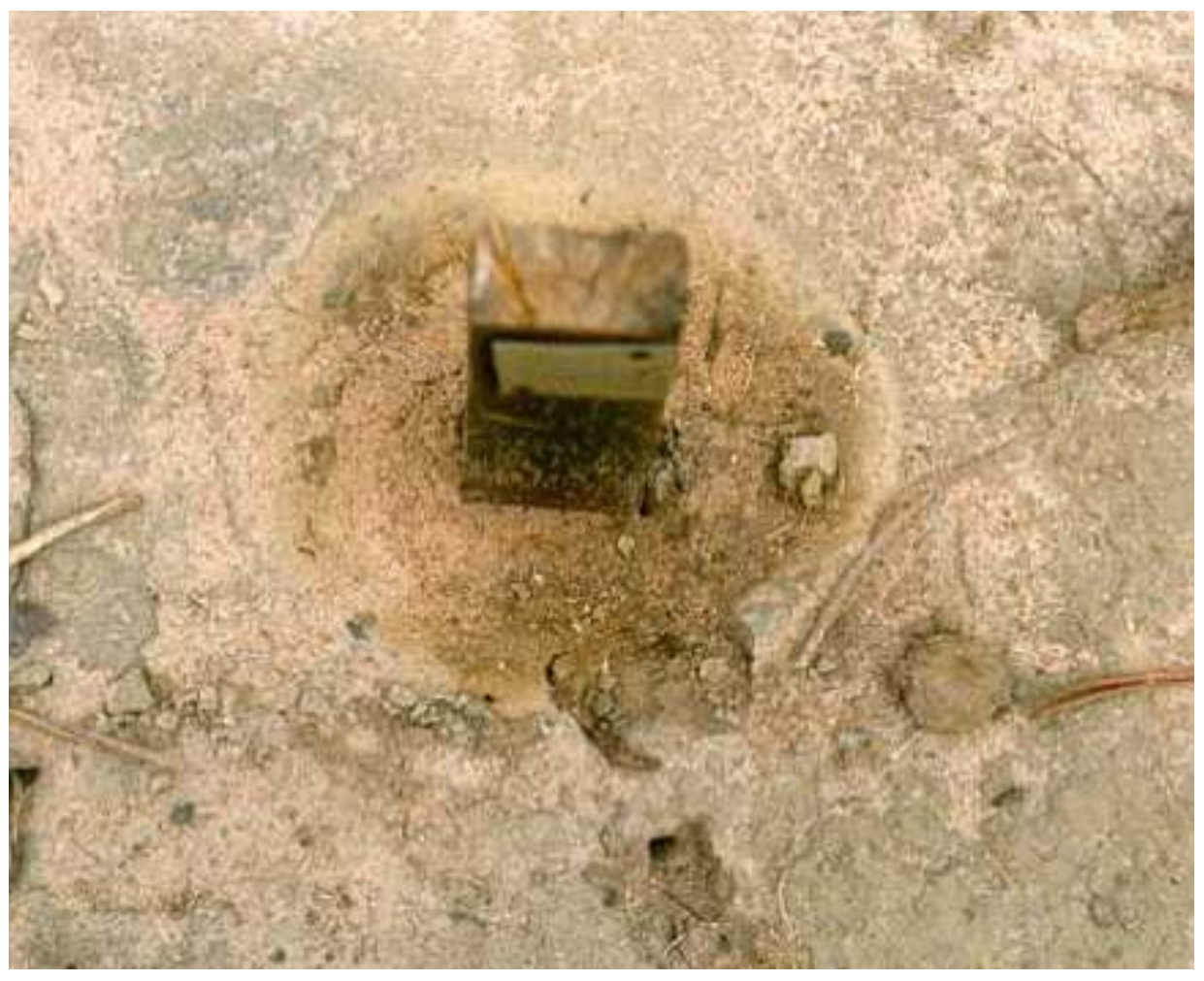

Figura 5 - llustrando o possível deslocamento do pentaclorofenol, da estaca para o solo. 
A partir dessa observação seria possível inferir que as falhas atuais têm como causa mais provável a deterioração biológica, porém a existência de falhas nitidamente mecânicas em outros tratamentos e a ausência de registros entre as avaliações comprometem conclusões categóricas.

O estado de sanidade das estacas remanescentes permite concluir que o pentaclorofenol, nas retenções estudadas, é menos eficiente que o CCA e o CCB, mas é impossível determinar a vida média com confiabilidade.

Considerando a eficiência inferior do pentaclorofenol, as limitações quanto à caracterização das falhas e as restrições legais e ambientais quanto à utilização do produto, optou-se por excluir o pentaclorofenol do ensaio em andamento e das discussões dos resultados. Assim, a análise de variância (Tabela 14) foi aplicada aos tratamentos com CCA-A, CCA-B, CCA-C e CCB, considerando como resultado do ensaio a durabilidade das estacas, após 21 anos de exposição, expressa pelo Índice de Comportamento.

Tabela 14. Resultado da análise de variância.

\begin{tabular}{lcccc}
\hline \multicolumn{1}{c}{ Fatores } & $\begin{array}{c}\text { Graus de } \\
\text { Liberdade }\end{array}$ & $\begin{array}{c}\text { Quadrado } \\
\text { médio }\end{array}$ & Valor de F & Probabilidade > F \\
\hline Espécie (E) & 3 & 96,9 & 0,66 & 0,5779 \\
Produto (P) & 3 & 2717,1 & 18,45 & $0,0001^{*}$ \\
Retenção (R) & 4 & 1224,7 & 8,31 & $0,0001^{*}$ \\
E x P & 9 & 217,1 & 1,47 & 0,1540 \\
E x R & 12 & 180,7 & 1,23 & 0,2600 \\
P x R & 12 & 365,1 & 2,48 & $0,0036^{*}$ \\
E x P X R & 36 & 99,1 & 0,67 & 0,9286 \\
(Tratamentos) & $(79)$ & 334.08 & 2,27 & 0,0001 \\
Resíduo & 579 & 147,31 & & \\
Total & 659 & & & \\
\hline
\end{tabular}

$\left({ }^{*}\right)=$ diferença significativa entre os fatores. 
Pelo quadro da análise de variância não detecta-se diferença significativa para o fator espécie de madeira. Já os fatores produto (CCA-A, CCA-B, CCA-C e CCB) e nível de retenção apresentaram diferenças significativas entre si, assim como o efeito da interação produto e retenção (PxR).

Tabela 15. Comparação entre as médias* dos diferentes produtos, pelo teste Tukey.

\begin{tabular}{cccc}
\hline & \multicolumn{2}{c}{ Índice de Comportamento } \\
CCA-A & CCA-B & CCA-C & CCB \\
\hline $94,6^{\mathbf{a}}$ & $94,5^{\mathbf{a}}$ & $91,4^{\mathrm{a}}$ & $85,8^{\mathrm{b}}$
\end{tabular}

$\left(^{*}\right)$ valores com letras iguais não diferem entre si ao nível de 5\% de probabilidade.

Analisando a Tabela 15, que apresenta a comparação entre médias para os produtos, nota-se que os três tipos de CCA são iguais entre si e diferentes do CCB.

Assim, até o momento da presente pesquisa, as diferentes formulações do CCA não influenciaram na durabilidade das estacas, e o produto CCB apresentou desempenho inferior quando comparado aos três tipos do CCA utilizadas neste estudo.

Este comportamento era esperado, tendo em vista observações de outros pesquisadores. Fernandes et al. (1990), ao relatar a avaliação do mesmo campo aos 111 meses de exposição, observaram a tendência do CCB apresentar desempenho ligeiramente inferior; embora a diferença não tivesse sido considerada como estatisticamente significativa. Resultado similar foi também relatado por Lopez et al. (1984), ao comparar a durabilidade da madeira de Pinus elliottii tratada com CCA-A, CCA-B e CCB após 4 anos de exposição em campo de apodrecimento.

Segundo Connell (1991), o arsênio presente na formulação do CCA é altamente tóxico e estável nas peças de madeira tratada, enquanto o 
boro (componente com característica inseticida do CCB) é menos resistente a lixiviação, o que pode comprometer o desempenho do produto a longo prazo, principalmente em situações de grande risco de deterioração.

Tabela 16. Comparação entre as médias* dos diferentes níveis de retenção, pelo teste Tukey.

\begin{tabular}{cllll}
\hline \multicolumn{5}{c}{ Índice de Comportamento } \\
R1 & $\mathbf{R 2}$ & $\mathbf{R 3}$ & R4 & R5 \\
\hline $88,7^{\text {a }}$ & $88,1^{\text {a }}$ & $92,4^{\text {ab }}$ & $93,7^{\text {b }}$ & $95,1^{\text {b }}$ \\
\hline
\end{tabular}

$\left(^{*}\right)$ valores com letras iguais não diferem entre si ao nível de $5 \%$ de probabilidade.

Na Tabela 16 é apresentada a comparação entre médias para os níveis de retenção. Nota-se que os níveis de retenção mais baixos (R1 e R2) apresentaram diferença significativa em relação às retenções mais altas ( $R 4$ e R5), comprovando que, dentro dos tratamentos estudados na presente pesquisa, o nível de retenção influenciou na durabilidade das estacas.

Este também era um resultado provável, pois, embora contradizendo informações da literatura, era de se esperar que as menores retenções resultassem em menores Índices de Comportamento (durabilidade).

Lopez et al. (1984), ao estudar o efeito da retenção na durabilidade de estacas de Pinus elliottii tratadas com preservantes hidrossolúveis, após 4 anos de exposição, obteve médias muito próximas em todos os níveis de retenção (que variaram de 4,9 a $13,5 \mathrm{~kg} / \mathrm{m}^{3}$ ). Fernandes et al. (1990), ao avaliar o mesmo campo da presente pesquisa aos 111 meses, também não verificou influência dos níveis de retenção na durabilidade das estacas. A evolução no Índice de Comportamento ao longo do tempo, tanto em relação aos produtos como aos níveis de retenção, reforça a importância dos estudos de longo prazo em campos de apodrecimento; pois os resultados obtidos até o momento comprovam a influência do tempo de exposição na performance da madeira tratada. 
Tabela 17. Comparação entre as médias do Índice de Comportamento dos diferentes produtos dentro dos níveis de retenção, pelo teste Tukey $\left({ }^{*}\right)$.

\section{Médias do Índice de Comportamento}

Retenções

\begin{tabular}{|c|c|c|c|c|c|}
\hline Produtos & R1 & R2 & R3 & R4 & R5 \\
\hline CCA-A & $90,3^{a}$ & $95,2^{b}$ & $95,3^{b}$ & $96,9^{b}$ & $95,4^{b}$ \\
\hline CCA-B & $93,6^{c}$ & $93,3^{c}$ & $91,8^{c}$ & $96,5^{c}$ & $97,5^{\mathrm{c}}$ \\
\hline CCA-C & $83,3^{d}$ & 86,9 de & $94,4^{\text {ef }}$ & $96,6^{f}$ & $95,9^{\text {ef }}$ \\
\hline CCB & $87,4^{\mathrm{mn}}$ & $77,1^{\mathrm{m}}$ & $88,0^{\mathrm{mn}}$ & $84,7^{\mathrm{mn}}$ & $91,6^{n}$ \\
\hline
\end{tabular}

$\left(^{*}\right)$ valores com letras iguais em uma mesma linha, não diferem entre si ao nível de $5 \%$ de probabilidade.

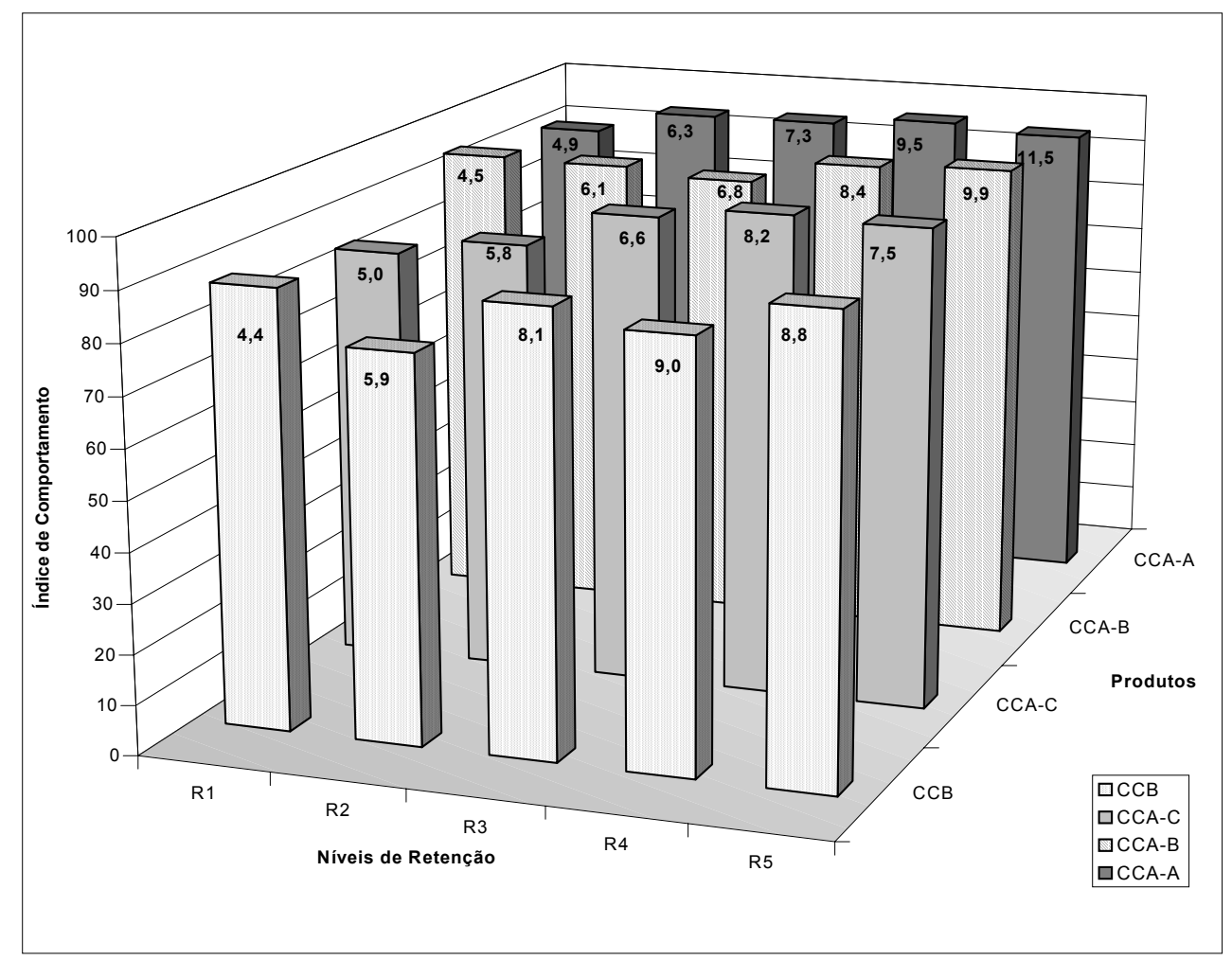

Figura 6 - Valores médios do Índice de Comportamento das espécies de madeira por produto e nível de retenção. (os valores nas barras correspondem a retenção média obtida por tratamento) 
A Tabela 17 apresenta a comparação entre médias dos níveis de retenção para cada um dos produtos ensaiados, ilustrada de forma gráfica na Figura 6.

Analisando-se o comportamento de cada produto, observa-se:

- o menor nível de retenção (R1) do CCA-A apresentou o menor Índice de Comportamento, e é diferente dos demais níveis de retenção;

- para o CCA-B não houve efeito significativo do nível de retenção no Índice de Comportamento;

- existe a tendência, no $C$ CA-C, de uma relação direta do Índice de Comportamento com o nível de retenção, com as médias menores nos níveis R1 e R2;

- no produto CCB não existe uma relação definida entre níveis de retenção e Índice de Comportamento. A diferença destacada como significativa na análise estatística é entre os níveis de retenção R2 e R5 (respectivamente, menor e maior Índice de Comportamento).

Com exceção do CCA-B, nos demais produtos o menor Índice de Comportamento corresponde aos menores níveis de retenção (R1 para CCA-A e CCA-C, R2 para o CCB); resultado coerente com a comparação entre níveis de retenção apresentada na Tabela 16.

A análise dos resultados obtidos até 0 momento permitem concluir que retenções menores implicam em Índices de Comportamento também menores (com exceção do CCA-B); porém é importante destacar que o efeito do nível de retenção no Índice de Comportamento não apresenta um mesmo padrão para todos os produtos sob análise (Figura 6).

Esta observação corrobora o efeito do tempo de exposição, enfatizando a importância dos ensaios de longo prazo na correta avaliação da durabilidade da madeira tratada. 
A comparação entre as combinações de produtos e níveis de retenção pode ser examinada na Tabela 18. Observa-se que os melhores desempenhos correspondem aos tratamentos com CCA (tipos A, B e C) nos níveis de retenção R4 e R5 (retenções variando de 7,5 a $11,5 \mathrm{~kg} / \mathrm{m}^{3}$ ).

Tabela 18. Comparação entre os valores médios do Índice de Comportamento para os diferentes produtos, por nível de retenção $\left({ }^{\star}\right)$.

\begin{tabular}{|c|c|c|c|}
\hline Produto & $\begin{array}{l}\text { Nível de } \\
\text { Retenção }\end{array}$ & $\begin{array}{c}\text { Í.C } \\
\text { médio }\end{array}$ & Comparações \\
\hline CCA-B & R5 & 97,5 & $a$ \\
\hline CCA-A & R4 & 96,9 & a \\
\hline CCA-C & R4 & 96,6 & a \\
\hline CCA-B & R4 & 96,6 & a \\
\hline CCA-C & R5 & 95,9 & a \\
\hline CCA-A & R5 & 95,4 & a \\
\hline CCA-A & R3 & 95,3 & $a b$ \\
\hline CCA-A & $\mathrm{R} 2$ & 95,2 & $a b$ \\
\hline CCA-C & R3 & 94,4 & $a b$ \\
\hline CCA-B & $\mathrm{R} 2$ & 93,3 & $a b c$ \\
\hline CCA-B & $\mathrm{R} 1$ & 93,6 & $a b c$ \\
\hline CCA-B & R3 & 91,8 & $a b c$ \\
\hline CCB & R5 & 91,6 & $a b c$ \\
\hline CCA-A & $\mathrm{R} 1$ & 90,3 & $a b c$ \\
\hline CCB & R3 & 88,0 & $a b c$ \\
\hline CCB & $\mathrm{R} 1$ & 87,4 & abcd \\
\hline CCA-C & $\mathrm{R} 2$ & 86,9 & abcd \\
\hline ССВ & R4 & 84,7 & bcd \\
\hline CCA-C & R1 & 83,4 & $\mathrm{~cd}$ \\
\hline CCB & $\mathrm{R} 2$ & 77,1 & $d$ \\
\hline
\end{tabular}

$\left(^{*}\right)$ médias com pelo menos uma letra igual, não diferem entre si ao nível de $5 \%$ de probabilidade. 
Esse resultado é concordante com as informações publicadas pelo United States Department of Agriculture, Forest Service - USDA, (Estados Unidos, 1991), o qual relata um ensaio de campo em que 70 a $100 \%$ de estacas tratadas com CCA-A e CCA-B, em retenções entre 6,1 e $10,4 \mathrm{~kg} / \mathrm{m}^{3}$, não apresentavam indícios de deterioração após 22 anos de exposição.

Nesse mesmo artigo (Estados Unidos., 1991) é possível verificar também o efeito do tempo de exposição. Estacas tratadas com CCA-B, em retenções acima de $12,5 \mathrm{~kg} / \mathrm{m}^{3}$, apresentaram-se totalmente sadias após 50 anos de exposição em campo; enquanto que $90 \%$ das estacas com retenção de $4,0 \mathrm{~kg} / \mathrm{m}^{3}$ encontravam-se deterioradas.

Os menores Índices de Comportamento correspondem aos tratamentos com CCA-C (níveis de retenção R1 e R2) e com CCB (níveis de retenção R1, R2 e R4). Contudo, a vida média estimada para os tratamentos, com menor Índice de Comportamento, através do ábaco de McLean, é da ordem de 30 anos.

A partir destas constatações é importante destacar as seguintes observações:

- o tratamento preservativo aumenta consideravelmente a durabilidade da madeira de Pinus, mesmo para os produtos ou níveis de retenção que, até o momento, apresentam os menores Índices de Comportamento;

- é necessário dar continuidade ao experimento, visando obter indicações mais seguras sobre a performance dos diferentes produtos e níveis de retenção.

Independentemente das diferenças constatadas entre produtos e níveis de retenção, os resultados permitem concluir que o tratamento preservante confere durabilidade a madeira de Pinus com uma expectativa de vida média superior a 30 anos. 


\subsection{Confirmação da sanidade biológica}

A análise macroscópica da amostra de madeira coletada em campo indicava ataque por fungos de podridão mole, pois apresentava a camada superficial amolecida e fissuras paralelas a grã (Figura 7).

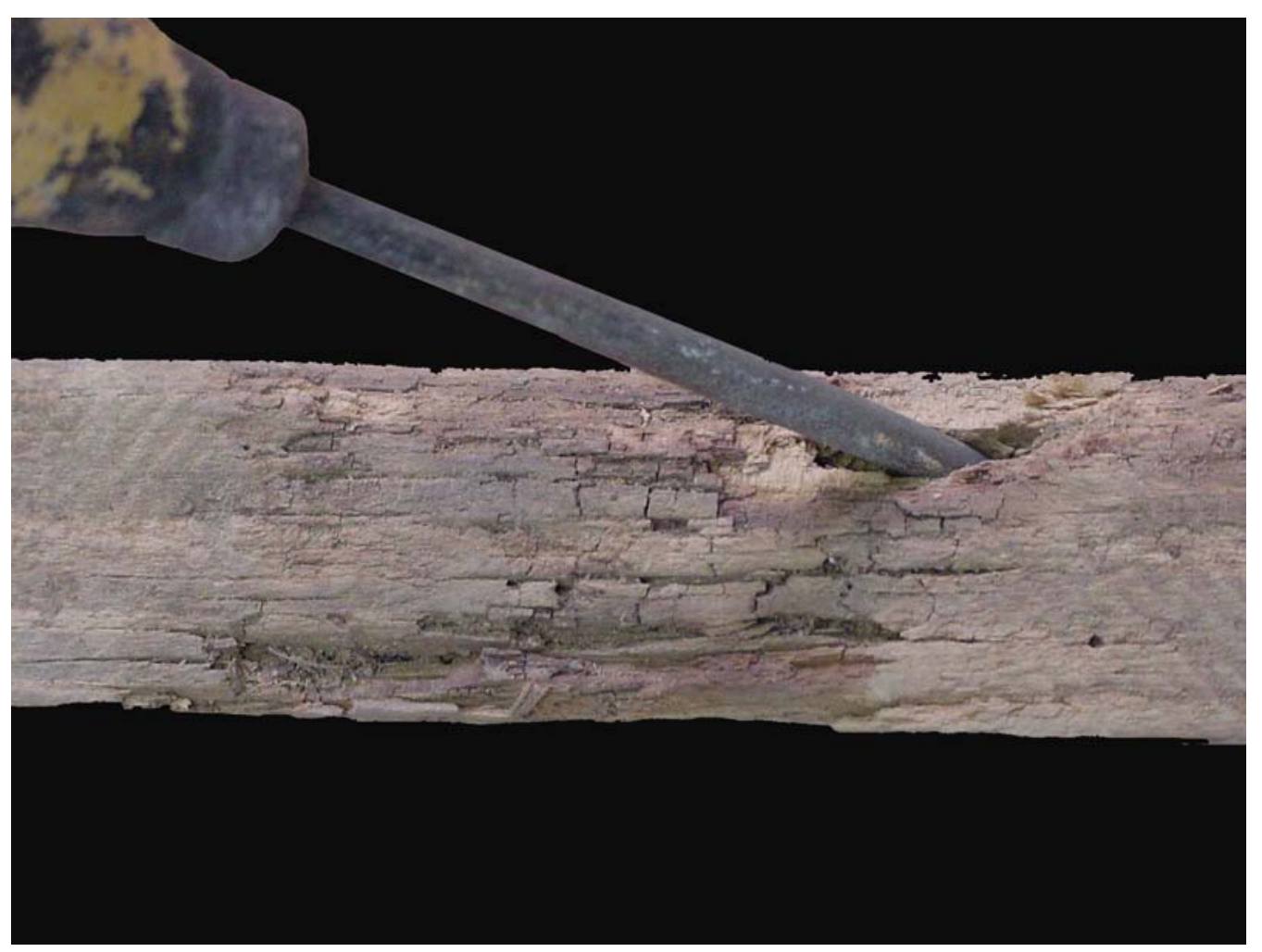

Figura 7 - Aspecto macroscópico de deterioração por fungo de podridão mole.

A analise microscópica das lâminas preparadas a partir dessa amostra confirmou a deterioração por fungos de podridão mole devido a presença de cavidades nas paredes celulares (Figuras 8 e 9), que é um padrão característico do apodrecimento causado por esse tipo de fungo (Zabel, 1992; Eaton, 1993). 


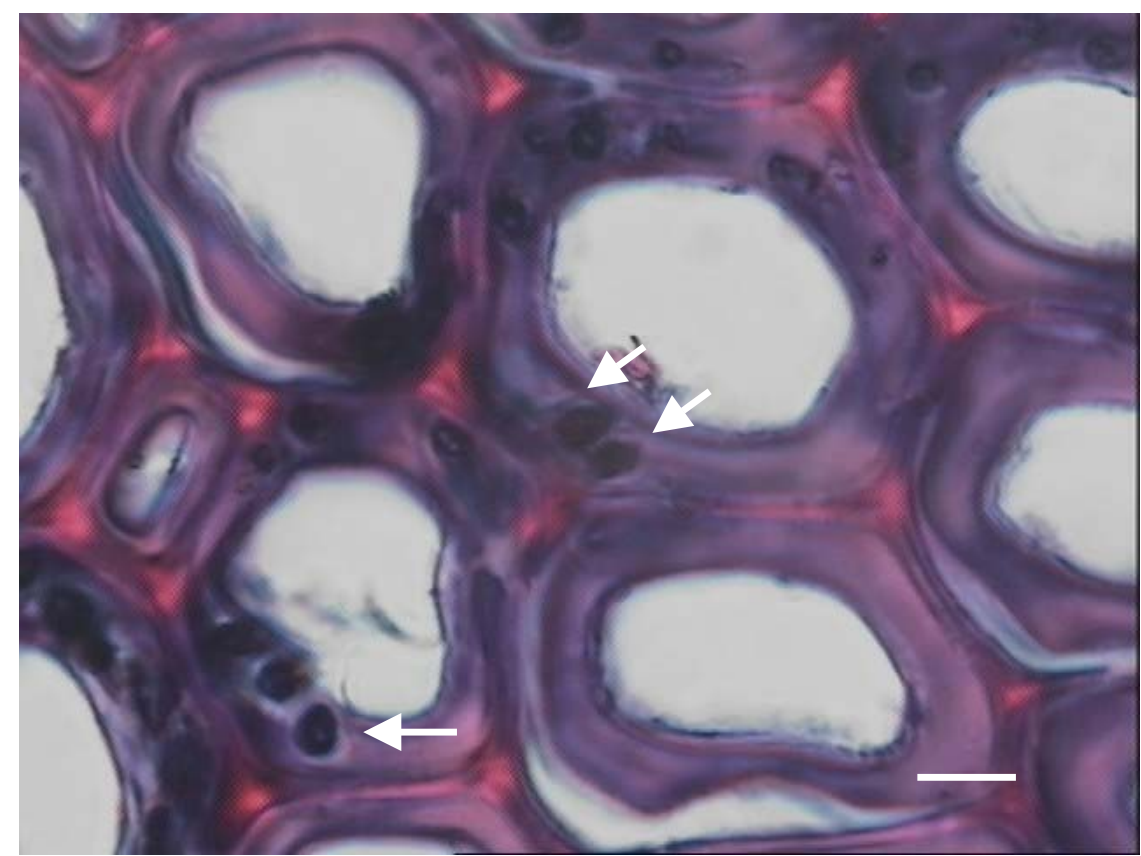

Figura 8 - Aspecto microscópico de ataque por fungos de podridão mole, secção transversal, (escala $=2$ um).

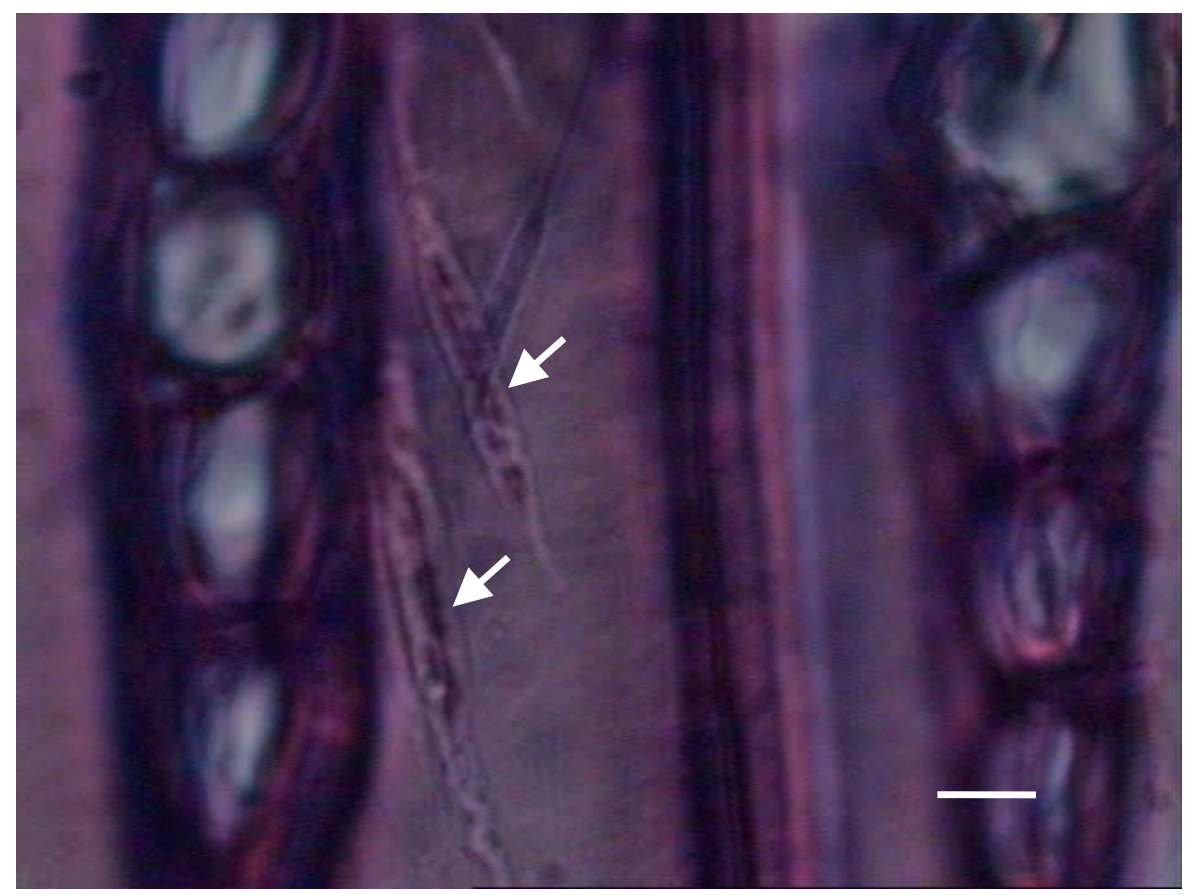

Figura 9 - Aspecto microscópico de ataque por fungos de podridão mole, secção longitudinal tangencial, (escala = 2um). 
Rayner \& Boddy (1988), Eaton (1993) e Drysdale (1984), relatam a presença desse tipo de deterioração em madeiras tratadas com arsenato de cobre cromatado (CCA), o mesmo produto aplicado a estaca de onde foi retirada a amostra para análise microscópica. Esse fato, segundo Nicholas (1985), é devido a existência de algumas espécies de fungos tolerantes ao cobre e outras tolerantes ao arsênio. Oliveira et al. (1986), falam ainda de espécies de fungos de podridão mole resistentes a altas concentrações de preservantes salinos e capazes de detoxificar os preservantes.

A Figura 10 mostra um detalhe do ataque de cupins em uma das estacas do campo de Mogi-Guaçu.

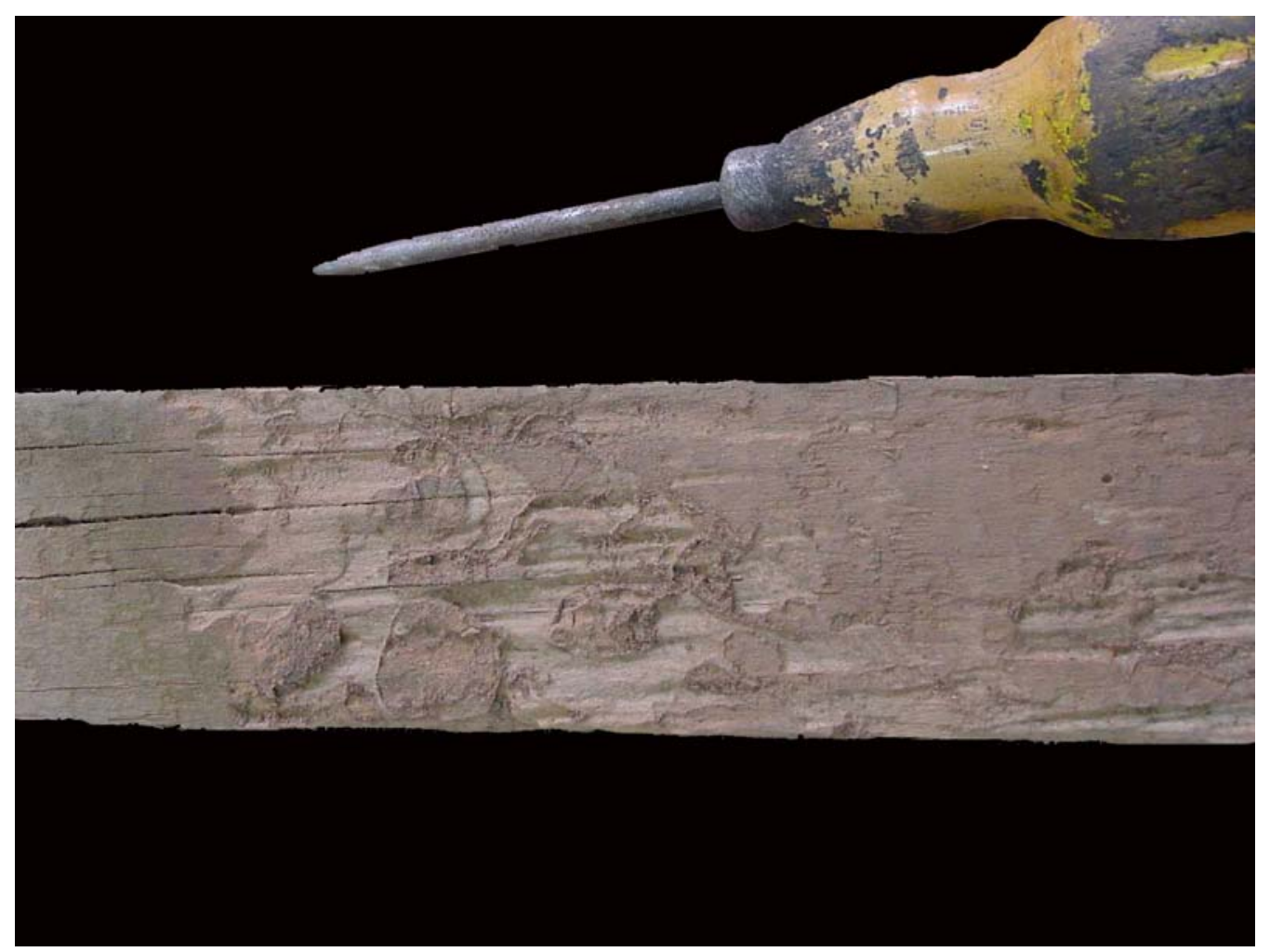

Figura 10 - Aspecto de estaca atacada por cupim subterrâneo. 
Os cupins coletados no campo de Mogi-Guaçu foram identificados como: Nasutitermes sp, da subfamília Nasutitermitinae, família Termitidae; e Heterotermes $\mathrm{sp}$, da subfamília Heterotermitinae, família Rhinotermitidae.

A ocorrência do gênero Nasutitermes nesta localidade ainda não havia sido registrada por outros autores, enquanto que o gênero Heterotermes foi identificado na mesma região por Cavalcante \& Lelis, 1974. 


\section{CONCLUSÕES}

Com base na discussão e análise dos resultados obtidos na atual avaliação das estacas, após 21 anos de exposição em campo, é possível concluir que:

- para as espécies sob ensaio, a madeira de Pinus tratada com preservantes hidrossolúveis (CCA ou CCB), em retenções superiores a $4,4 \mathrm{~kg} / \mathrm{m}^{3}$, pode ser considerada como durável;

- até o presente momento, a durabilidade da madeira tratada não apresentou diferença entre as espécies avaliadas;

- considerando os produtos isoladamente, a madeira tratada com CCB apresentou desempenho inferior ao da madeira tratada com CCA A, B e C;

- o nível de retenção influenciou na durabilidade das estacas, sendo que o melhor desempenho está associado com as retenções mais elevadas;

- a maior resistência a degradação biológica foi apresentada pela madeira tratada com as três formulações de CCA (tipos A, B e C), nas retenções acima de $7,5 \mathrm{~kg} / \mathrm{m}^{3}$;

- a vida-média estimada para a madeira com o pior desempenho em campo é da ordem de 30 anos;

- a durabilidade natural da madeira de Pinus (sem tratamento preservante) em contato direto com o solo é inferior a dois anos.

Adicionalmente, foi também possível:

- confirmar a ocorrência de podridão mole em madeira tratada com CCA;

- identificar a presença de cupins dos gêneros Nasutitermes e Heterotermes no campo de apodrecimento. 


\section{REFERÊNCIAS BIBLIOGRÁFICAS}

AGÊNCIA NACIONAL DE VIGILÂNCIA SANITÁRIA. Portaria $\mathbf{n}^{\circ}$ 329, de 02 de setembro de 1985.

http://www.anvisa.gov.br/legis/portarias/329 85.htm, (03 Nov. 2001).

ASSOCIAÇÃO BRASILEIRA DA INDÚSTRIA DE MADEIRA PROCESSADA MECANICAMENTE. Madeira processa mecanicamente Estudo Setorial. Curitiba, 2001. 27p.

ASSOCIAÇÃO BRASILEIRA DE CELULOSE E PAPEL. Relatório estatístico florestal 1999: GT - 7 Reflorestamentos e correlatos.

ASSOCIAÇÃO BRASILEIRA DOS PRESERVADORES DE MADEIRA. Preservação: durabilidade e qualidade na madeira; publicação comemorativa aos 25 anos da ABPM. São Paulo, 1993. 26p.

ALEXOPOULOS, C. J.; MINS, C. W.; BLACKWELL, M. Introductory mycology. 4. ed. New York: John Wiley, 1996. 868p.

AMEMIYA, S.; COCKCROFT, R. Wood preservation in Japan. Stockholm: Swedish National Board for Technical Development, 1982. 88p. (Information, 272).

ANAGNOST, S. E. Light microscopic diagnosis of wood decay. IAWA Journal, v.19, n.2, p. $141-167,1998$.

BANDA, E. J. K .B.; TWESIGYE-OMWE, M. N. Effects of creosote oil on the mechanical properties of selected uganda timbers. Forest Products Journal, v.47, n.10, p.56-58, 1997.

BESNER, A.; GILBERT, R. TETREAULT, P.; LABRECQUE, J.F. Effect of weathering exposure on the preservative and softening agent retention, wood hardness and climbability of CCA treated red pine utility poles. Forest Products Journal, v.49, n.10, p.59-68, 1999. 
BERTI FILHO, E. Manual de pragas em florestas: cupins ou térmitas. Piracicaba: IPEF, SIF, 1993. $56 \mathrm{p}$.

BRAZOLIN, S. Podridão mole em madeira de Tabebuia sp. (ipê) em torre de resfriamento de água: identificação e avaliação da capacidade de degradação dos fungos e alterações na estrutura anatômica da madeira. Piracicaba, 1997. 140 p. Dissertação (Mestrado) - Escola Superior de Agricultura "Luiz de Queiroz", Universidade de São Paulo.

BURGERS, N.; COCKCROFT, R.; JONG, D. de. Wood preservation in the Netherlands. Stockholm: Swedish National Board for Technical Development, 1985. 72p.( Information, 457).

CAVALCANTE, M. S. Preservação de madeiras no Brasil. São Paulo: Instituto de Pesquisas Tecnológicas do Estado de São Paulo S.A., 1979. 23 p. (IPT. Publicação, 1122).

CAVALCANTE, M. S. Deterioração biológica e preservação de madeiras., São Paulo: Instituto de Pesquisas Tecnológicas do Estado de São Paulo S.A., 1982a. 40 p. (IPT. Publicação, 1211).

CAVALCANTE, M. S. Wood-attacking organisms in Brazil. In: ANNUAL MEETING, 13., Turkey, 1982. Proceedings. Stockholm: The International Research Group on Wood Preservation, 1982b. 20p. (IRG/WP/1168).

CAVALCANTE, M. S. Implantação e desenvolvimento da preservação de madeiras no Brasil. Pesquisa \& Desenvolvimento, v.14, p. 1-57, 1983.

CAVALCANTE, M. S. Histórico da preservação de madeiras. In: LEPAGE, E.S., (Ed.) Manual de preservação de madeiras. São Paulo: IPT,SICCT, 1986. v.1, cap.2, p.9-20.

CAVALCANTE, M. S.; LELIS, A. T. de. Organismos xilófagos coletados nos campos de apodrecimento instalados pelo convênio IPT-IF em diversas regiões do estado de São Paulo. Preservação de Madeira, v. 5, n. 1, p. 29-50, jan./dez. 1974.

CAVALCANTE, M. S.; COCKCROFT, R. Wood preservation in Brazil. Stockholm: Swedish National Board for Technical Development, 1984. 68p. (Information, 445)

COCKCROFT, R. Wood preservation in the United Kingndon. Stockholm: Swedish National Board for Technical Development, 1979. 56p.(Information, 153). 
COCKCROFT, R. Wood preservation in U.S.A. Stockholm: Swedish National Board for Technical Development 1981. 50p. (Information, 152).

COCKCROFT, R.; WILLEITNER, H. Wood preservation in the Federal Republic of Germany. Swedish National Board for Technical Development (Information, 214), 53p. 1981.

CONNELL, M. Industrial wood preservatives - the history, development, use, advantages and future trends. In: THOMPSON, R. The chemistry of wood preservation. London: The Royal Society of Chemistry, 1991. $315 p$.

CONSTANTINO, R. Chave ilustrada para identificação dos gêneros de cupins (Insecta: Isoptera) que ocorrem no Brasil. Papéis Avulsos de Zoologia, v. 40, n. 25, p.387-448, 1999.

COSTA, L. A. M. Cupins urbanos: conhecer para combater. Ciência Hoje, v. 28 , n. 165 , p. 74-77, out. 2000.

DRYSDALE, J. Comparison of the effect of different soil sources of the type and ratie of decay of CCA treated pine exposed in soil-bed. In: ANNUAL MEETING, 13., Turkey, 1984. Proceedings. Stockholm: The International Research Group on Wood Preservation, 1982. 15p. (IRG/WP/2213).

EATON, R. A.; HALE, M. D. C. Wood: decay, pests and protection. London: Chapman \& Hall, 1993. 546p.

EDWARDS, R.; MILL, A. E. Termites in buildings: their biology and control. East Grinstead: Rentokil, 1986. 261 p.

EVANS, P. D.; BEUTEL, P. J.; DONNELLY, C.; CUNNINGHAM, R. B. Surface Checking of CCA-treated Radiata Pine Decking Timber Exposed to Natural Weathering. In: ANNUAL MEETING, 31., Kona, 2000. Proceedings. Stockholm: The International Research Group on Wood Preservation, 2000. 12p. (IRG/WP/00-40165).

ESTADOS UNIDOS. Department of Agriculture Forest service. Comparison of preservatives in stake tests. Madison, 1991. 123p.

FERNANDES, P. S. de., MONTAGNA, R. G.; JANKOWSKY, I.P.; CAVALCANTE, A. A. de. Estudo comparativo da durabilidade de Pinus spp tratados com Preservativos de Madeira. In: CONGRESSO FLORESTAL BRASILEIRO, 6., Campos do Jordão, 1990. Anais. São Paulo: SBS; SBEF, 1990. v.1, p. 689-695. 
FONTES, L. R. Cupins em áreas urbanas. In: BERTI, E.F Alguns aspectos atuais da biologia e controle de cupins. Piracicaba: FEALQ, 1995. p. 57-75.

FONTES, L. R.; BERTI FILHO, E. (Ed.) Cupins: o desafio do conhecimento. Piracicaba: FEALQ, 1998. 512 p.

FREITAS, A. R. de. Consulta mundial sobre o uso da madeira na habitação. Preservação de Madeiras, v.2, n. 1, p. 63-87, jan./dez. 1971.

GALVÃO, A. P. M.; BARBIN D.; CARVALHO, C. M. Contribuição ao estudo da eficiência dos processos de difusão simples e dupla no tratamento de moirões de eucalipto, através de análise química. Silvicultura em São Paulo, v. 6, p.301-324, 1967.

GOLFARI, L.; CASER, R. L.; MOURA, V. P. G. Zoneamento ecológico e esquemático para reflorestamento no Brasil. Belo Horizonte: Centro de Pesquisa Florestal da Região do Cerrado, 1978, 66 p.(Série Técnica, 11).

GREAVES, H. Wood preservation in Australia. Stockholm: Swedish National Board for Technical Development 1984. 62p. (Information, 438).

HEDLEY, M.; PAGE, D.; PATTERSON, B. Long term performance of CCA preservatives in ground contact. In: ANNUAL MEETING, 31., Kona, 2000. Proceedings. Stockholm: The International Research Group on Wood Preservation, 2000. 15p. (IRG/WP/00-30223).

HUNT, G. M.; GARRAT, G. A. Wood preservation.3. ed New York: MacGraw-Hill, 1953. 417p.

JANKOWSKY, I. P. Melhorando a qualidade e a durabilidade das madeiras através do tratamento preservativo. In: CONGRESSO FLORESTAL BRASILEIRO, 7., Curitiba, 1993. Anais. São Paulo: SBS; SBEF, 1993. v.3, p. 304-306.

JANKOWSKY, I. P.; MONTAGNA, R. G.; FERNANDES, P. S. Utilização de moirões de Pinus ratados com preservativos de madeira. In: ENCONTRO BRASILEIRO EM PRESERVAÇÃO DE MADEIRAS, 3., São Paulo, 1989. Anais. São Paulo: ABPM; IPT, 1989. p.219-224.

JESUS, M. A.; MORAIS, J. W.; ABREU, R. L. S.; CARDIAS, M. F. C. Durabilidade natural de 46 espécies de madeira amazônicas em contato com o solo em ambiente florestal. Scientia Forestalis, n.54, p.81-92, dez.1998. 
JUNQUEIRA, L. K. Cupins (Insecta: Isoptera) em plantios de Eucalyptus spp. (Myrtacea) na Estação Experimental de Ciências Florestais da Universidade de São Paulo, no município de Anhembi, São Paulo. Piracicaba, 1999. 57 p. Dissertação (Mestrado) - Escola Superior de Agricultura "Luiz de Queiroz", Universidade de São Paulo.

LELIS, A. T. de. Termite problem in São Paulo City - Brazil. In: CONGRESS OF THE INTERNATIONAL UNION FOR THE STUDY OF SOCIAL INSECTS (IUSSI), 12., Paris, 1994. Abstracts. Paris: IUSSI, 1994. p. 253.

LELIS, A. T. de. Insetos deterioradores de madeira no meio urbano. Série Técnica IPEF, v. 13, n.33, p. 81-90, mar. 2000.

LEPAGE, E. S. Método padrão sugerido pela IUFRO para ensaios de campo com estacas de madeira. Preservação de Madeiras, v. 1 n.4, p.205-216, dez. 1970.

LEPAGE, E. S.; MONTAGNA, G. R. Estudo de preservativos de madeira e processos de Tratamento. Boletim Técnico do Instituto Florestal, v.7, p.1-8, dez. 1973.

LEPAGE, E. S. Preservativos e sistemas preservativos. In: LEPAGE, E.S., (Coord.) Manual de preservação de madeiras. São Paulo: IPT; SICCT, 1986. v.1, cap. 6, p 279-330.

LEPSCH, I. F. Solos: formação e conservação. São Paulo: Melhoramentos; EDUSP, 1977. 158 p.

LOPEZ, G. A. C. Effectiveness of wood preservatives by IUFRO's method. In: ANNUAL MEETING, 15., Sweden, 1984. Proceedings. Stockholm: The International Research Group on Wood Preservation, 1984. (IRG/WP/3305).

LOPEZ, G. A. C.; MILANO. S. Avaliação da durabilidade natural da madeira e de produtos usados na sua proteção. In: LEPAGE, E.S., (Coord.) Manual de preservação de madeiras. São Paulo: IPT; SICCT, 1986.v.2, cap.10, p 473-510.

MARER, P., GRIMES, M. Wood preservation. Oakland: University of California, 1992. 92p.

MINISTÉRIO DE MINAS E ENERGIA. Balanço Energético Nacional, 2000. 
MORAES, M. A. F. D. A indústria da madeira preservada no Brasil: um estudo de sua organização industrial. Piracicaba, 1996a. 173 p. Dissertação (Mestrado) - Escola Superior de Agricultura "Luiz de Queiroz", Universidade de São Paulo.

MORAES, M. A. F. D.; BACHA, C.J.C. Indústria de madeira preservada. Preços Agrícolas, v.10, n.115, p. 2 - 5 maio 1996b.

NICHOLAS, D. D. Wood preservation and its prevention by preservatives treatments. Suni: Syracuse University Press, 1985. v.1, $380 p$.

NILOUFARI, P.; COCKCROFT, R. Wood preservation in Iran. Stockholm: Swedish National Board for Technical Development, 1984. 39p. (Information n. 412)

NILSSON, T. Deffining fungal decay types - final proposal. In: ANNUAL MEETING, 19., Madri, 1988. Proceedings. Stockholm: The International Research Group on Wood Preservation, 1988. (IRG/WP/1355).

NILSSON, T. Soft-rot fungi - decay patterns and enzyme production. Material und Organismen, v.3, p.103-112, s.d.

OLIVEIRA, A. M. F.; LELIS, A. T. de; LEPAGE, E. S.; LOPEZ, G. A. C.; OLIVEIRA, L. C. S. de; CAÑEDO, M. D.; MILANO, S. Agentes destruidores da madeira. In: LEPAGE, E.S. (Coord.) Manual de preservação de madeiras. São Paulo: IPT; SICCT, 1986. v.1, cap.5, p.99-278.

OLIVEIRA, A. M. F.; LEPAGE, E. S. Controle de qualidade. In: LEPAGE, E.S. (Coord.) Manual de preservação de madeiras. São Paulo: IPT, SICCT, 1986. v.1, cap.5, p.99-278.

PRESTON, A. F. Wood preservation: Trends of today that influence the industry tomorrow. Forest Products Journal, v. 50, n. 9, Sep. 2000.

PROGRAMA DE QUALIFICAÇÃO E CERTIFICAÇÃO DO CARVÃO VEGETAL NO ESTADO DE SÃO PAULO. Relatório descritivo SEBRAE. São Paulo, 2000. 68p. /No prelo/.

RAYNER, A. D. M.; BODDY, L. Fungal decomposition of wood: its biology and ecology. Chichester:John Wiley, 1988. $587 \mathrm{p}$. 
REIMÃO, D.; COCKCROFT, R. Wood preservation in Portugal. Stockholm: Swedish National Board for Technical Development, 1985. 94p. (Information, 487).

REIS, J. E. B. A avaliação do comportamento da madeira tratada através de ensaios de campo. Separata Técnica, v. 350, p. 641-648, 1965.

RICHARDSON, B. A. Wood preservation. 2. ed. London: E \& F Spon, 1993. $226 \mathrm{p}$.

ROCHA, M. P. Biodegradação e preservação da madeira. Curitiba: FUPEF, Universidade Federal do Paraná, 2000. 94 p.

ROMA, A. L. de.; COCKCROFT, R. Wood preservation in Spain. Stockholm: Swedish National Board for Technical Development, 1983. 57p. (Information n. 373).

STEVENS, M.; COCKCROFT, R. Wood preservation in Belgiun. Stockholm: Swedish National Board for Technical Development 1981. 38p. (Information, 234).

TABACOF, B. Avaliação do setor de celulose e papel (http://www.bracelpa.com.br/Portugues/Aval2000.html (5 dez. 2001).

VAN ACKER, J.; STEVENS, M.; COMVALIUS, L. Variation in field test performance of untreated and CCA-treated lesser-known surinamese wood species. In: ANNUAL MEETING, 31., Kona, 2000. Proceedings. Stockholm: The International Research Group on Wood Preservation, 2000. 8p. (IRG/WP/00-20213).

VITOR, M. A. M.; MONTAGNA ,R. G. Análise panorâmica da situação florestal e efeito da lei dos incentivos fiscais em São Paulo. Silvicultura em São Paulo, v.7, p.7-18, 1970.

WATAI, L.T. Substituição de Espécies de Madeiras Nativas por Madeiras de Reflorestamento. In: CONGRESSO FLORESTAL BRASILEIRO, 6.,Campos de Jordão, 1990. Anais. São Paulo: SBS; SBEF, 1990. v.1, p. 131-133.

WILKINSON, J. G. Industrial timber preservation. London: Associates Business Press, 1979. 531p.

ZABEL, R. A.; MORREL, J. J. Wood microbiology decay and Its prevention., New York: Academic Press, 1992. 432p. 
APÊNDICE 
APÊNDICE - Tabelas de freqüência do Índice de Comportamento

Tabela 19. Freqüência do Índice de Comportamento das estacas de Pinus elliottii Engl. var. elliottii, após 252 meses de exposição, no campo de Mogi-Guaçu.

\begin{tabular}{|c|c|c|c|c|c|c|c|}
\hline \multirow[t]{2}{*}{ Produto } & \multirow[t]{2}{*}{ N.R. ${ }^{*}$} & \multicolumn{6}{|c|}{ Índice de Comportamento } \\
\hline & & 100 & 90 & 70 & 40 & 0 & total \\
\hline \multirow{5}{*}{ CCA-A } & 1 & 2 & 2 & 3 & 1 & & 8 \\
\hline & 2 & 5 & 3 & & & & 8 \\
\hline & 3 & 4 & 4 & & & & 8 \\
\hline & 4 & 7 & 1 & & & & 8 \\
\hline & 5 & 5 & 2 & 1 & & & 8 \\
\hline \multirow{5}{*}{ CCA-B } & 1 & 5 & 2 & 1 & & & 8 \\
\hline & 2 & 5 & 3 & & & & 8 \\
\hline & 3 & 3 & 5 & 1 & & & 9 \\
\hline & 4 & 4 & 4 & & & & 8 \\
\hline & 5 & 8 & & & & & 8 \\
\hline \multirow{5}{*}{$\mathrm{CCA}-\mathrm{C}$} & 1 & & 6 & 2 & & & 8 \\
\hline & 2 & 1 & 8 & & & & 9 \\
\hline & 3 & 2 & 4 & 1 & & & 7 \\
\hline & 4 & 7 & 2 & & & & 9 \\
\hline & 5 & 4 & 4 & 1 & & & 9 \\
\hline \multirow{5}{*}{ CCB } & 1 & 3 & 4 & 1 & & 1 & 9 \\
\hline & 2 & & 2 & 6 & & & 8 \\
\hline & 3 & 1 & 4 & 4 & & & 9 \\
\hline & 4 & 2 & 5 & 1 & & & 8 \\
\hline & 5 & 1 & 6 & 1 & & & 8 \\
\hline \multirow{5}{*}{ Pentaclorofenol } & 1 & & & & & 1 & 1 \\
\hline & 2 & & & & 4 & 2 & 6 \\
\hline & 3 & & & 1 & 2 & 2 & 5 \\
\hline & 4 & & & 3 & & & 3 \\
\hline & 5 & & & 2 & & 2 & 4 \\
\hline
\end{tabular}


Tabela 20. Freqüência do Índice de Comportamento das estacas de Pinus caribaea Mor. var. hondurensis, B \& G., após 252 meses de exposição, no campo de Mogi-Guaçu.

\begin{tabular}{|c|c|c|c|c|c|c|c|}
\hline \multirow[t]{2}{*}{ Produto } & \multirow[t]{2}{*}{ N. $\mathbf{R}^{*}$} & \multicolumn{6}{|c|}{ Índice de Comportamento } \\
\hline & & 100 & 90 & 70 & 40 & 0 & total \\
\hline \multirow{5}{*}{ CCA-A } & 1 & 4 & 3 & & & & 7 \\
\hline & 2 & 4 & 5 & & & & 9 \\
\hline & 3 & 6 & 1 & & & & 7 \\
\hline & 4 & 4 & 4 & & & & 8 \\
\hline & 5 & 6 & 2 & & & & 8 \\
\hline \multirow{5}{*}{ CCA-B } & 1 & 2 & 6 & & & & 8 \\
\hline & 2 & 4 & 3 & & & 1 & 8 \\
\hline & 3 & 3 & 5 & 1 & & & 9 \\
\hline & 4 & 5 & 3 & & & & 8 \\
\hline & 5 & 7 & 2 & & & & 9 \\
\hline \multirow{5}{*}{ CCA-C } & 1 & 1 & 4 & 2 & & 1 & 8 \\
\hline & 2 & 5 & & & & 1 & 6 \\
\hline & 3 & 5 & 2 & & & & 7 \\
\hline & 4 & 3 & 3 & & & & 6 \\
\hline & 5 & 6 & 2 & & & & 8 \\
\hline \multirow{5}{*}{ ССВ } & 1 & & 7 & & & & 7 \\
\hline & 2 & & 5 & 2 & & 1 & 8 \\
\hline & 3 & 1 & 6 & 1 & & & 8 \\
\hline & 4 & 1 & 6 & & 1 & & 8 \\
\hline & 5 & 3 & 4 & 1 & & & 8 \\
\hline \multirow{5}{*}{ Pentaclorofenol } & 1 & & & & 1 & 1 & 2 \\
\hline & 2 & & & & 1 & 3 & 4 \\
\hline & 3 & & & & 2 & 2 & 4 \\
\hline & 4 & & & & 4 & 1 & 5 \\
\hline & 5 & & & 1 & 4 & & 5 \\
\hline
\end{tabular}


Tabela 21. Freqüência do Índice de Comportamento das estacas de Pinus kesiya Royle ex Gordon após 252 meses de exposição, no campo de Mogi-Guaçu.

\begin{tabular}{|c|c|c|c|c|c|c|c|}
\hline \multirow[t]{2}{*}{ Produto } & \multirow[t]{2}{*}{$\mathbf{N} \cdot \mathbf{R}^{*}$} & \multicolumn{6}{|c|}{ Índice de Comportamento } \\
\hline & & 100 & 90 & 70 & 40 & 0 & total \\
\hline \multirow{5}{*}{ CCA-A } & 1 & 1 & 8 & & & & 9 \\
\hline & 2 & 5 & 2 & & & & 7 \\
\hline & 3 & 3 & 5 & & & & 8 \\
\hline & 4 & 5 & 3 & & & & 8 \\
\hline & 5 & 1 & 6 & & & & 7 \\
\hline \multirow{5}{*}{ CCA-B } & 1 & 3 & 6 & & & & 9 \\
\hline & 2 & 6 & 2 & & & & 8 \\
\hline & 3 & 1 & 7 & & & & 8 \\
\hline & 4 & 7 & 2 & & & & 9 \\
\hline & 5 & 5 & 4 & & & & 9 \\
\hline \multirow{5}{*}{ CCA-C } & 1 & & 6 & 1 & & & 7 \\
\hline & 2 & 4 & 5 & & & & 9 \\
\hline & 3 & 5 & 4 & & & & 9 \\
\hline & 4 & 7 & 2 & & & & 8 \\
\hline & 5 & 6 & 3 & & & & 9 \\
\hline \multirow{5}{*}{$\mathrm{CCB}$} & 1 & & 7 & 1 & & & 8 \\
\hline & 2 & & 6 & 1 & & 1 & 8 \\
\hline & 3 & 2 & 5 & 2 & & & 9 \\
\hline & 4 & 5 & & 2 & & 1 & 8 \\
\hline & 5 & 2 & 7 & & & & 9 \\
\hline \multirow{5}{*}{ Pentaclorofenol } & 1 & & & 1 & & & 1 \\
\hline & 2 & & & 1 & & & 1 \\
\hline & 3 & & & & 3 & 2 & 5 \\
\hline & 4 & & & 1 & 4 & & 5 \\
\hline & 5 & & & 1 & 3 & 2 & 6 \\
\hline
\end{tabular}


Tabela 22. Freqüência do Índice de Comportamento das estacas de Pinus oocarpa Shied, após 252 meses de exposição, no campo de MogiGuaçu.

\begin{tabular}{|c|c|c|c|c|c|c|c|}
\hline \multirow[t]{2}{*}{ Produto } & \multirow[t]{2}{*}{$\mathbf{N} \cdot \mathbf{R}^{*}$} & \multicolumn{6}{|c|}{ Índice de Comportamento } \\
\hline & & 100 & 90 & 70 & 40 & 0 & tota \\
\hline \multirow{5}{*}{ CCA-A } & 1 & 2 & 5 & 1 & & & 8 \\
\hline & 2 & 2 & 7 & & & & 8 \\
\hline & 3 & 3 & 6 & & & & 9 \\
\hline & 4 & 6 & 2 & & & & 8 \\
\hline & 5 & 8 & 1 & & & & 9 \\
\hline \multirow{5}{*}{ CCA-B } & 1 & 2 & 6 & & & & 8 \\
\hline & 2 & 5 & 4 & & & & 9 \\
\hline & 3 & 3 & 5 & & & & 8 \\
\hline & 4 & 6 & 3 & & & & 9 \\
\hline & 5 & 6 & 3 & & & & 9 \\
\hline \multirow{5}{*}{ CCA-C } & 1 & 2 & 3 & 2 & 1 & & 8 \\
\hline & 2 & 1 & 6 & 1 & & 1 & 8 \\
\hline & 3 & 6 & 1 & 1 & & & 8 \\
\hline & 4 & 4 & 3 & & & & 7 \\
\hline & 5 & 5 & 2 & & & & 7 \\
\hline \multirow{5}{*}{ ССВ } & 1 & 1 & 8 & & & & 9 \\
\hline & 2 & 2 & 3 & 4 & & & 9 \\
\hline & 3 & 3 & 6 & & & & 9 \\
\hline & 4 & 2 & 6 & 1 & & & 9 \\
\hline & 5 & 4 & 5 & & & & 9 \\
\hline \multirow{5}{*}{ Pentaclorofenol } & 1 & & & 1 & 1 & & 2 \\
\hline & 2 & & & & 2 & & 2 \\
\hline & 3 & & & & 3 & 2 & 5 \\
\hline & 4 & & & & 6 & 1 & 7 \\
\hline & 5 & & & 2 & 5 & & 7 \\
\hline
\end{tabular}

